\title{
Aerosol retrievals using rotating shadowband spectroradiometer data
}

\author{
S. M. Gianelli \\ Department of Applied Physics and Applied Mathematics, Columbia University, New York, New York, USA
}

NASA Goddard Institute for Space Studies, New York, New York, USA

B. E. Carlson and A. A. Lacis

NASA Goddard Institute for Space Studies, New York, New York, USA

Received 9 August 2004; revised 5 November 2004; accepted 10 December 2004; published 5 March 2005.

[1] The rotating shadowband spectroradiometer (RSS) is a high-resolution device that measures the total, direct, and diffuse intensity of sunlight at 1016 different wavelengths. RSS data can be used to retrieve gas amounts and aerosol properties as well as to assess the accuracy of retrievals using data from lower-spectral resolution instruments, such as the multifilter rotating shadowband radiometer (MFRSR). An algorithm to retrieve aerosol and gas amounts and the aerosol size distribution from RSS data, using the full resolution and using selected wavelengths, has been developed (Gianelli, 2004). The results of the retrievals, applied to RSS data from the southern Great Plains (SGP) site, indicate a number of things about the aerosol size distribution and our ability to retrieve aerosol information accurately. First, we show that the aerosol size distribution at SGP is at least bimodal. The notion that a more complex size distribution can be modeled with an appropriately selected monomodal distribution produces an unacceptable fit to the data once the separation of aerosol extinction from nitrogen dioxide absorption at short wavelengths is taken into consideration. Second, we find that the amount of retrievable aerosol information is limited by the wavelength range of the data. This is exemplified by the indeterminacy of the coarse-mode effective radius and the interdependence in the retrievals of the fine-mode effective radius and effective variance. Third, when the fine-mode effective variance is constrained, an annual cycle in fine-mode effective radius values emerges from the retrieval results, with a maximum in March and a minimum in September. Conceivably, changes in the effective variance could influence the observed pattern as well. The large margin of error in the coarse-mode effective radius leads to relatively small error bars for the coarse- and fine-mode optical depths, the fine-mode effective radius, and ozone, except on those days when the coarse-mode optical depth is high. Examining the retrieval results for different wavelength combinations of five RSS channels allows us to investigate whether or not the MFRSR channels are optimized to retrieve aerosol information or if a different filter set would increase the robustness of the retrievals. We show that replacing the $670 \mathrm{~nm}$ channel with one at either 375 or $1034 \mathrm{~nm}$ improves the retrieval accuracy. In particular, retrievals with the $1034 \mathrm{~nm}$ channel very closely reproduce the full RSS retrieval results, provided that the $\mathrm{NO}_{2}$ column amount can be determined by other means. The precision of the retrieved values of the fine-mode effective radius is shown to be strongly sensitive to the precision of measured $\mathrm{NO}_{2}$ amounts; a margin of error in column $\mathrm{NO}_{2}$ of 0.3 Dobson units results in a corresponding margin of error of $0.04 \mu \mathrm{m}$ in the fine-mode effective radius. This confirms that aerosol sizes cannot be inferred accurately from optical depth spectra alone if either the amount of $\mathrm{NO}_{2}$ above a site is unknown or an inaccurate value is assumed.

Citation: Gianelli, S. M., B. E. Carlson, and A. A. Lacis (2005), Aerosol retrievals using rotating shadowband spectroradiometer data, J. Geophys. Res., 110, D05203, doi:10.1029/2004JD005329.

\section{Introduction}

[2] The most recent report of the Intergovernmental Panel on Climate Change [2001] indicated that the role of anthropogenic aerosols in climate change remains, in a 
understanding of the direct effect of sulfates was rated as "low," while the level of understanding of the direct effect of all the other aerosol types, along with the indirect effect, was rated as "very low." In other words, much more work needs to be done in the study of every facet of aerosols. This includes improving the techniques used to monitor aerosols from satellites, airplanes, and the ground. Not only aerosol amounts but also their physical and radiative properties need to be measured better.

[3] One of these properties is the aerosol size distribution. Improved measurement of aerosol sizes will enhance the understanding of not only the direct effect but the indirect effect as well. This is true because the number of aerosol particles, and therefore potential cloud condensation nuclei, in a given air mass can be inferred if the aerosol extinction and size distribution have both been accurately determined. In addition, since gases like ozone $\left(\mathrm{O}_{3}\right)$ and nitrogen dioxide $\left(\mathrm{NO}_{2}\right)$ absorb at wavelengths relevant to the analysis of aerosols, these gases also need to be measured with as much accuracy as possible. A complete assessment of aerosol properties is only possible to the degree that the respective contributions of aerosols and gases to the total extinction at solar wavelengths can be separated. Significantly, nitrogen dioxide absorbs most strongly in the blue region of the spectrum at $415 \mathrm{~nm}$, where some devices have their shortest wavelength. As Schroeder and Davies [1987] demonstrated, $\mathrm{NO}_{2}$ absorption is too significant to ignore if aerosols are to be measured accurately. Overestimating $\mathrm{NO}_{2}$ amounts will lead to retrieved particle sizes that are too large, while underestimating $\mathrm{NO}_{2}$ or ignoring it entirely will make the particles seem smaller than they actually are.

[4] The rotating shadowband spectroradiometer (RSS) contains a high-resolution array of over 1000 channels [Harrison et al., 1999]. Its spectral resolution simplifies the separation of the competing extinctions due to aerosols and gases, especially $\mathrm{NO}_{2}$. While this gives the RSS an advantage over other monitoring devices, only one RSS device, at the southern Great Plains (SGP) site in Oklahoma, is presently in operation because of its large cost. Another RSS briefly operated at the North Slope site in Alaska, and others will be deployed in Beltsville, Maryland, and Golden, Colorado. No algorithm for retrieving either aerosol size distribution properties or column $\mathrm{NO}_{2}$ amounts using RSS data existed prior to the work of Gianelli [2004].

[5] Networks of different monitoring devices have been established across the country and the globe in the hope of obtaining aerosol optical depth and size distribution values on large spatial scales and timescales. One such device used in these networks is the multifilter rotating shadowband radiometer (MFRSR) [Harrison et al., 1994]. The MFRSR was designed with filters right at the peak absorption wavelengths of ozone and nitrogen dioxide, and therefore the MFRSR retrieval algorithm of Alexandrov et al. [2002a] was designed to solve for gas amounts, aerosol properties, and calibration simultaneously. This algorithm is based on a couple of assumptions whose accuracy can be tested using RSS data. First, the aerosol extinction curve can be adequately represented by a single-mode size distribution. Second, the algorithm also assumes that while the effective variance cannot be determined precisely, the actual values for the optical depth, the effective radius, ozone, and $\mathrm{NO}_{2}$ will be bracketed by the retrieved values for the extremes of the monomodal effective variance, 0.01 and 0.4 .

[6] The filters of the CIMEL Electronique 318A spectral radiometer, the device of choice for the aerosol robotic network (AERONET) [Holben et al., 1998], avoid peaks in gas absorption bands. AERONET obtains aerosol optical depth measurements by subtracting the optical depth due to assumed climatological values for ozone [London et al., 1976] and neglecting $\mathrm{NO}_{2}$ absorption. An algorithm for calculating the aerosol size distribution [Dubovik and King, 2000] from both aerosol optical depth spectra and angular sky radiance distributions, allowing for the possibility of multiple aerosol modes, has recently been developed for use with AERONET data. In addition, O'Neill et al. [2001] developed an algorithm to measure the coarse- and finemode optical depths in a bimodal distribution using only CIMEL spectral optical depth data.

[7] Alexandrov et al. [2002b] examined several years worth of MFRSR data at a number of different sites, including the SGP site in Oklahoma. Most of the sites showed a strong seasonal cycle in aerosol optical depth, with maximum values in the summer and minimum values in winter or late autumn. For the three sites in the northeastern United States the annual mean retrieved effective radius was $0.43 \mu \mathrm{m}$, with higher values in winter than in summer. Retrieved column $\mathrm{NO}_{2}$ values tended to be on the order of several Dobson units, much larger than the values obtained from Global Ozone Monitoring Experiment (GOME) satellite retrievals [Velders et al., 2001] over the SGP site, and showed a strong correlation with aerosol optical depth values at each site. The AERONET aerosol climatology [Holben et al., 2001], though, used the Angstrom coefficient $(\alpha)$ to infer information about the aerosol size distribution at a number of sites in their network, including the SGP site. Using data from 1994 to 1999, Holben et al. found lower values for $\alpha$ (implying larger aerosol sizes) in late winter and early spring at SGP and found larger values for $\alpha$ (implying smaller sizes) in late summer and fall. They calculated the highest monthly mean value for $\alpha$ at the SGP site in December but with a limited number of days relative to the other months in the sample. The lowest monthly value of $\alpha$ still exceeded 1 , though, meaning that the aerosol extinction steadily decreased with wavelength even for the largest aerosols observed. The effective radius values reported in the Alexandrov et al. [2002b] MFRSR climatology for the SGP site, being large enough to cause an increase in extinction with wavelength at least in the violet part of the spectrum, do not agree with this result.

[8] This paper is an extension of the portion of the work presented by Gianelli [2004] that pertained to the retrieval of aerosol amounts and properties using RSS data. Additional emphasis is given to the error analysis and to the precision with which the various quantities can be retrieved under different circumstances. The algorithm used to analyze the RSS data is summarized in section 2. Section 3 examines the retrieval results using the full RSS data, showing which quantities can and cannot be adequately measured with the data and explaining how to work within and around the limitations of the data set. The RSS is also useful in that it can produce MFRSR "equivalent" data by isolating the RSS wavelengths corresponding to the central wavelengths of the MFRSR filters. As section 4 shows, this 
enables a test of the measurement potential of the wavelength combination traditionally used in the MFRSR; it is concluded that a different combination of wavelengths would produce better results. Section 5 summarizes the results and suggests possible routes to improve the quality of aerosol retrievals in the future.

\section{Data and Methods}

[9] The SGP site in Oklahoma houses a wide variety of monitoring devices. The RSS located at SGP belongs to the Atmospheric Radiation Measurement (ARM) Program of the Department of Energy, and the data set used for this study spans a year, from July 1999 to July 2000. Morning and afternoon means of optical depth values, with the Rayleigh contribution subtracted, were used to perform the retrievals. These optical depth values were determined through the use of Langley regressions and were validated using the ARM/ National Institute of Standards and Technology (NIST) "working standard," a mean of three NIST standard lamps [Harrison et al., 2003]. According to Harrison et al. [1999] the optical depth uncertainty is 0.01 for most of the wavelength range of the RSS, but it increases to 0.02 at ultraviolet wavelengths. Cloudy points are filtered out using the objective algorithm of Harrison and Michalsky [1994]. This process first eliminates regions where the first derivative of the measured voltage with respect to air mass is positive and then removes data points spanning an equal length of time immediately before these regions. Points where the first derivative is too strongly negative are then also removed, and then a preliminary regression is used to further remove stray points before a final regression is taken. The data set used for this study consists of mornings and afternoons for which a Langley regression was obtainable.

\subsection{Aerosol Retrieval Algorithm for the RSS}

[10] Hansen and Travis [1974] identified three specific properties of aerosols that need to be measured in order for Mie scattering to completely describe the extinction of a given mass of aerosols as a function of wavelength. One of these, the single-scattering albedo, is the ratio of the extinction due to scattering to the total extinction. Strongly absorbing aerosols like soot can have values for the singlescattering albedo significantly $<1$. The remaining properties are the effective radius and effective variance. The effective radius is defined by the following formula:

$$
r_{\mathrm{eff}}=\frac{\int_{0}^{\infty} r \pi r^{2} n(r) d r}{\int_{0}^{\infty} \pi r^{2} n(r) d r},
$$

where $n(r) d r$ is the fraction of particles between the radii $r$ and $r+d r$, or the fractional size distribution of the aerosols. The effective variance is then defined as

$$
v_{\mathrm{eff}}=\frac{\int_{0}^{\infty}\left(r-r_{\mathrm{eff}}\right)^{2} \pi r^{2} n(r) d r}{r_{\mathrm{eff}}^{2} \int_{0}^{\infty} \pi r^{2} n(r) d r} .
$$

where $q_{\lambda}$ is the aerosol extinction coefficient normalized to unity at $550 \mathrm{~nm}, \tau_{a 550}$ is the aerosol optical depth at $550 \mathrm{~nm}$,

It is a measure of the spread of the particles around a central size. In an aerosol size distribution with a small effective variance the particles will be roughly the same size, while a large effective variance means a broader range of sizes.

[11] The size distribution does not always follow a simple, bell-shaped curve, however. A number of different mathematical forms have been applied to aerosol size distributions, including gamma, lognormal, and power law. When the effective variance is small, the difference in extinction caused by altering the assumed shape of the aerosol size distribution is negligible. Furthermore, even when the effective variance becomes large, limits to the accuracy of retrieved values of the effective radius and variance, coupled with the inability to retrieve from the data more than two or three items of independent aerosol information, make a clear determination of the shape of the aerosol size distribution impossible. The gamma size distribution, used in the Goddard Institute for Space Studies radiative transfer models, is chosen because the absence of broad "tails" in the size distribution simplifies the analysis of multiple aerosol modes, or distinct groups of aerosols with their own values for the effective radius and variance. As the determination of the presence of multiple aerosol modes is one of the key objectives of this study, all Mie scattering calculations performed for this study assume a gamma distribution.

[12] The aerosol retrieval algorithm developed for the RSS incorporates the notion, postulated by Box et al. [1996] and confirmed by Gianelli [2004] with an empirical orthogonal function (EOF) analysis of the RSS optical depth data, that at most, three independent items of aerosol information are obtainable from optical depth data in the RSS wavelength range. In fact, while the additional number of channels in the RSS does provide a minor benefit, the breadth of the range of wavelengths used in a device has a much greater impact on the retrievable aerosol information than does spectral detail within this wavelength range. We will show in this study that attempting to retrieve too much information not only results in errors but also potentially masks significant information about the aerosol size distribution contained within the data.

[13] In this algorithm the Mie scattering lookup tables used in the Alexandrov et al. [2002a] algorithm are expanded, with more wavelengths and a greater range of effective radius values, and a larger variance of 0.5 is added. The possible nonsphericity of aerosol particles is not considered because the difference in direct beam extinction between spherical and nonspherical particles is negligible [Mishchenko et al., 1997]. Since extra channels did produce a slight improvement in information retrievability in the EOF analysis, 16 RSS channels are used in the highest-resolution RSS aerosol retrieval. These channels, covering all MFRSR and CIMEL wavelengths plus the "window" regions where water vapor absorption is absent, are $380,400,415,440,450$, $500,525,550,585,610,670,750,780,870,1020$, and $1034 \mathrm{~nm}$. The total optical depth at a given wavelength can be defined by the simple linear equation

$$
\tau_{\lambda}=q_{\lambda} \tau_{a 550}+\alpha_{\lambda} \mathrm{NO}_{2}+\beta_{\lambda} \mathrm{O}_{3},
$$


and $\alpha_{\lambda}$ and $\beta_{\lambda}$ are the absorption coefficients of nitrogen dioxide and ozone, respectively. These coefficients for $\mathrm{NO}_{2}$ [Burrows et al., 1998] and ozone [Burrows et al., 1999] were obtained from GOME reference data. The full set of the optical depth equations can therefore be collectively expressed as a linear matrix equation, whose solution vector can be calculated by means of a brute force least squares regression. A series of iterations is performed for effective variance values of $0.01,0.1,0.2,0.3,0.4$, and 0.5 . The effective radius is steadily increased, with the Mie scattering coefficients adjusted accordingly. For each effective radius increment the least squares technique is performed, and the residual optical depth values are calculated by subtracting the measured optical depths from the calculated optical depths. The RMS residual is calculated for each radius value, and the iteration continues until the RMS residual for the new radius is greater than that for the previous radius, indicating that the minimum residual for that variance has been located. The radius/variance combination that produces the minimum overall RMS residual is output as the solution vector.

[14] The biggest asset of this algorithm is its flexibility. If desired, one can attempt to retrieve column amounts of ozone and nitrogen dioxide simultaneously with the aerosols. Aerosols can just as easily be retrieved separately from the gases by first subtracting gas optical depths, obtained from either climatology or high-resolution retrievals, from the total optical depth. It can also accommodate different combinations of wavelengths, which provides two significant benefits. First, the retrieval can be applied to data from the MFRSR and CIMEL in addition to the RSS. Second, and most importantly, the retrieval can be used with RSS data to examine how the quality of the results depends on the wavelengths used. Thus the algorithm could be used to evaluate if a different set of five wavelengths would produce better retrievals than the current MFRSR filter set.

\subsection{Retrieving Column $\mathrm{NO}_{2}$ Amounts From RSS Data}

[15] The specific technique generally used to measure the amounts of gases such as $\mathrm{NO}_{2}$ with high-resolution devices is called differential optical absorption spectroscopy (DOAS) [Platt et al., 1979]. DOAS looks at wavelengths where the absorption spectrum of a gas varies particularly rapidly relative to the smooth continuum of aerosol extinction and uses the difference in intensity measured in this spectral region to calculate the amount of that gas present in an atmospheric column. As an example, Harrison et al. [2003] used DOAS to infer a column $\mathrm{NO}_{2}$ amount from the SGP RSS data for the morning of 2 November 1999. Their reported value of 0.55 Dobson units (DU) $(1 \mathrm{DU}=0.001 \mathrm{~atm} \mathrm{~cm})$ was considered to be uncommonly large for the data set yet is still far smaller than the mean results for the SGP MFRSR reported by Alexandrov et al. [2002b].

[16] Unfortunately, the degree of random noise present in the RSS over the course of this data set is large enough to substantially compromise the accuracy of a straightforward DOAS retrieval [Gianelli, 2004]. As a prospective alternative approach a procedure was developed by Gianelli [2004] to circumvent this difficulty, owing more to the $k$ distribution method of Lacis and Oinas [1991] than it does to standard DOAS techniques. The effect of the random noise is mitigated in this procedure by averaging points that have been grouped together by $\mathrm{NO}_{2}$ absorption coefficient, not by wavelength. In addition, data points in the wavelength ranges found to be particularly sensitive to the Ring effect [Grainger and Ring, 1962] are excluded from the retrieval. This method depends on finding an adequate curve to represent the aerosol extinction, however, and a thorough investigation has shown the $\mathrm{NO}_{2}$ amounts retrieved in this manner to be extremely sensitive, on average, to the wavelength range chosen. By contrast, the mean $\mathrm{NO}_{2}$ value for the whole data set retrieved by DOAS techniques consistently clustered around $0.3 \mathrm{DU}$, regardless of the wavelength range used for the retrieval and in spite of very poor correlations due to random noise. As none of the wavelength ranges examined with the DOAS technique produce an unequivocal "best fit," the daily results presented here represent the mean of the $\mathrm{NO}_{2}$ amounts calculated using several different wavelength ranges, with the margin of error determined by the largest deviation from the mean for a given day.

\section{RSS Retrieval Results}

[17] This section begins with a demonstration of the inadequacy of single-mode retrievals, at least at the SGP site. An incorrect assumption about the nature of the aerosol size distribution in low-resolution retrievals will cause aerosol extinction to be mistakenly attributed to absorption by one of the gases or vice versa. When this happens, unnatural-looking correlations between gas and aerosol amounts, beyond what might be expected even from biomass burning and industrial pollutants, appear in the data. Once the necessity of a bimodal retrieval is established, the question then becomes which aerosol properties can be retrieved adequately and which require assumptions to be made. Section 3.2 shows that the fine- and coarse-mode optical depths are both retrievable. The fine-mode effective radius and effective variance are interdependent, but the effective radius can be retrieved as well if the variance is constrained. However, the coarse-mode effective radius is shown to be indeterminate given the wavelength range of the RSS. With these restrictions established, the retrievals are then redone. The results of this set of retrievals, presented in section 3.3, are considered to be the best results for the RSS data among the retrievals discussed in this paper.

\subsection{Inadequacy of Single-Mode Retrievals}

[18] For the RSS data, single-mode aerosol retrievals are performed two ways. First, ozone and nitrogen dioxide are retrieved simultaneously within the retrieval. Second, highresolution retrievals are used to measure the gases independently of the aerosols. Gas amounts retrieved in this manner ought to be more accurate, and these high-resolution retrievals serve as a test of the ability of low-resolution retrievals, whose use would be necessary for devices like the MFRSR, to adequately separate gas and aerosol extinction. The mean values of the retrieved quantities are presented in Table 1. For the effective variance, treated at this point as a retrievable quantity, the most commonly retrieved value is presented, along with the percentage of time this value is retrieved over the course of the data set. When $\mathrm{NO}_{2}$ is retrieved with low resolution instead of high 
Table 1. Mean Retrieved Values for the Single-Mode RSS Retrievals ${ }^{\mathrm{a}}$

\begin{tabular}{|c|c|c|c|c|c|c|}
\hline & $\begin{array}{c}\text { Mean Aerosol } \tau \text {, } \\
550 \mathrm{~nm}\end{array}$ & $\begin{array}{c}\text { Mean Effective } \\
\text { Radius, } \mu \mathrm{m}\end{array}$ & $\begin{array}{c}\text { Dominant Effective } \\
\text { Variance }^{\mathrm{b}}\end{array}$ & $\begin{array}{c}\text { Mean } \mathrm{NO}_{2}, \\
\text { DU }\end{array}$ & $\begin{array}{l}\text { Mean Ozone, } \\
\text { DU }\end{array}$ & $\begin{array}{c}\text { Mean RMS } \\
\text { Residual } \tau \\
\end{array}$ \\
\hline RSS, gases coupled & 0.064 & 0.290 & $0.5(87.4 \%)$ & 1.60 & 262 & 0.00289 \\
\hline RSS, gases retrieved separately & 0.071 & 0.200 & $0.5(92.9 \%)$ & $0.30 \pm 0.08$ & 279 & 0.00451 \\
\hline
\end{tabular}

${ }^{\mathrm{a}}$ When $\mathrm{NO}_{2}$ is retrieved with low resolution instead of high resolution, the values are much higher, resulting in a corresponding overestimation of the effective radius. In both cases the retrieved effective variance is usually the highest possible value. This is consistent with the likelihood of a bimodal or multimodal aerosol size distribution. The residual optical depth is higher for the high-resolution retrievals because an assumed single-mode size distribution does not fit the data well unless some aerosol extinction in the lower wavelengths is mistakenly attributed to $\mathrm{NO}_{2}$. RSS is rotating shadowband spectroradiometer; DU is Dobson units $(1 \mathrm{DU}=0.001 \mathrm{~atm} \mathrm{~cm})$.

${ }^{\mathrm{b}}$ Value in parentheses is the percentage of time the dominant effective variance is retrieved over the course of the data set.

resolution, the values for both $\mathrm{NO}_{2}$ and the effective radius are much higher. Either way, though, the retrieved effective variance is usually the highest possible value.

[19] Figure 1 shows the plots of the aerosol optical depth at $550 \mathrm{~nm}$ for the 16-channel, single-mode, coupled aerosolgas retrievals versus day. The plot shows a seasonal cycle, with maximum optical depth values in the summer and minimum values in winter. The maximum value does not exceed 0.25. A couple of days in August of 1999, for which the CIMEL located at the Cloud and Radiation Testbed (CART) site measured optical depth values larger than 0.3 , were not present in the RSS data set. The effective radius values are presented in Figure 2. While the value exceeds $0.4 \mu \mathrm{m}$ on several days, the mean value of $0.290 \mu \mathrm{m}$ is substantially lower than the mean of $0.43 \mu \mathrm{m}$ reported by Alexandrov et al. [2002b] for the MFRSR at the SGP site, consistent with an overestimation of $\mathrm{NO}_{2}$. No evidence of a seasonal cycle is present in the data. With these retrievals it is also possible to retrieve the effective variance, although it is not clear that the variance can be determined uniquely. The largest variance, 0.5 , is retrieved $87.4 \%$ of the time. Taken by itself, this result could conceivably be indicative of physical reality. However, this is also the anticipated result if a single-mode retrieval is applied to data from a site where the aerosols are bimodal or multimodal.
[20] The column $\mathrm{NO}_{2}$ values are plotted versus day in Figure 3. The retrieved $\mathrm{NO}_{2}$ values follow a similar pattern to the measured optical depth values, and as Figure 4 shows, the correlation between retrieved $\mathrm{NO}_{2}$ and aerosol optical depth is quite high, just as was reported by Alexandrov et al. [2002b]. The mean value of 1.60 DU is lower than the MFRSR value reported by Gianelli [2004], even for the highest variance, using the Alexandrov et al. [2002a] algorithm. However, these values also turn out to be too high. Figure 5 shows the single-mode RSS retrieval projected over the full spectrum for the morning of 23 June 2000 , when the aerosol optical depth was particularly large but the change in aerosol extinction with wavelength was relatively small. The retrieved value of $\mathrm{NO}_{2}$ greatly overestimates the variation in optical depth that is actually observed in the spectral region where $\mathrm{NO}_{2}$ strongly absorbs, establishing unambiguously that some aerosol extinction is indeed being incorrectly attributed to $\mathrm{NO}_{2}$ absorption in the low-resolution retrievals.

[21] Because of its utilization of the full spectral resolution of the RSS, which enables the signal of nitrogen dioxide absorption to emerge distinctly from the aerosol background, the DOAS $\mathrm{NO}_{2}$ retrieval algorithm should produce more accurate results than any low-resolution retrieval which attempts to retrieve aerosol and $\mathrm{NO}_{2}$

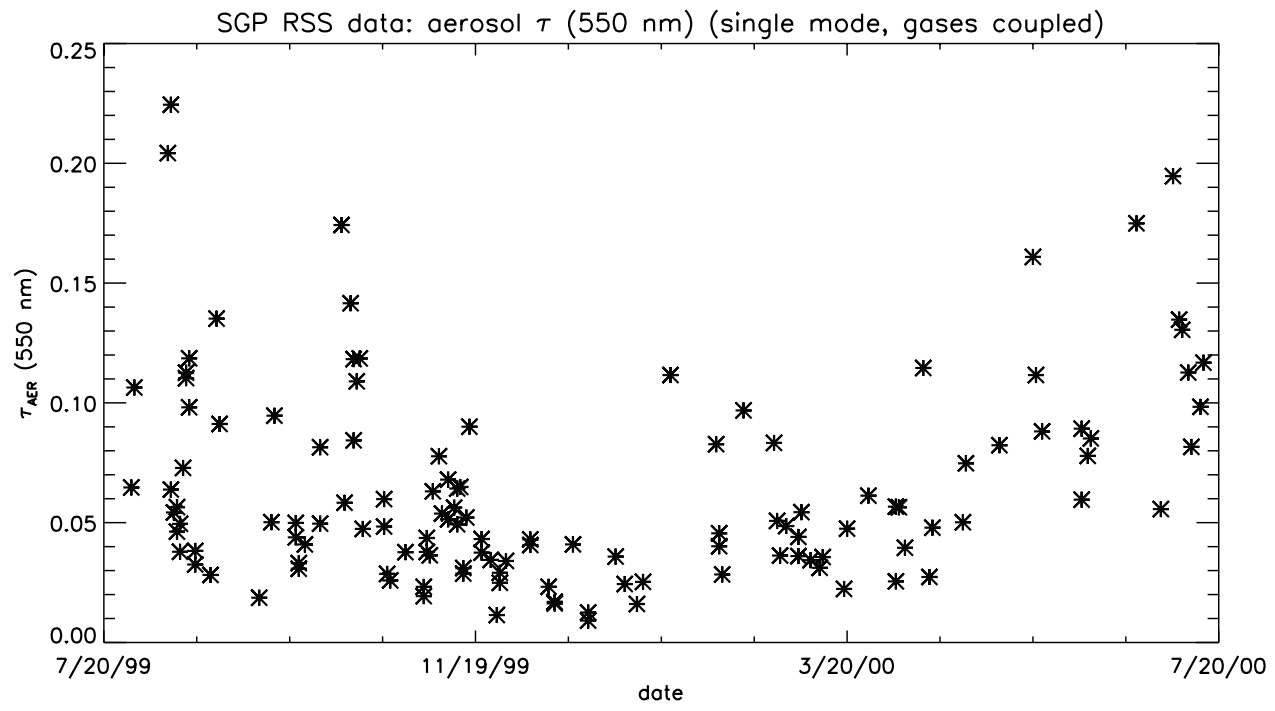

Figure 1. Plot of aerosol optical depth at $550 \mathrm{~nm}$ versus day, as determined by the coupled aerosol-gas retrieval, assuming a single-mode aerosol size distribution. The optical depth values show a seasonal pattern with a maximum in summer and a minimum in winter. Sharp relative peaks occur in August and October 1999. 


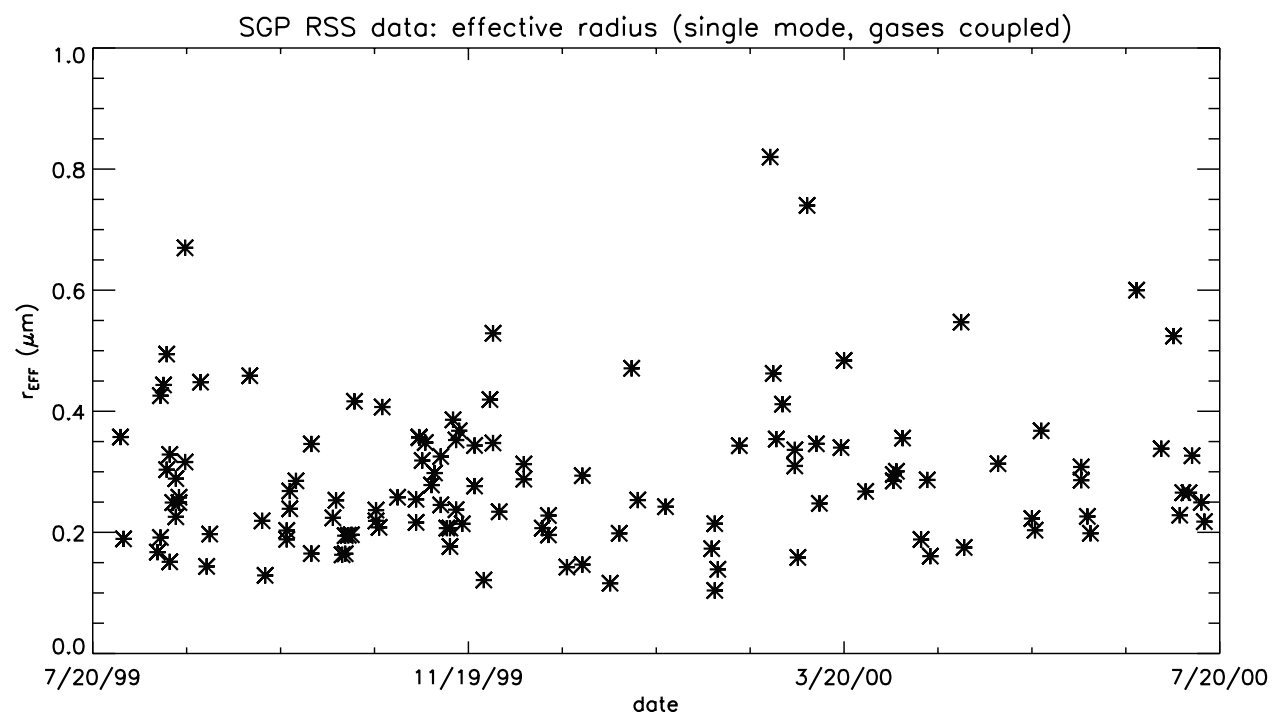

Figure 2. Plot of the effective radius versus day, as determined by the coupled aerosol-gas retrieval, assuming a single-mode aerosol size distribution. Many of the values exceed $0.4 \mu \mathrm{m}$, for which the aerosol extinction curve would increase with wavelength in the violet region of the spectrum. Such behavior was not reported in the Aerosol Robotic Network (AERONET) aerosol climatology [Holben et al., 2001]. In addition, no evidence of a seasonal pattern in the data is readily apparent.

amounts simultaneously. The results of the high-resolution $\mathrm{NO}_{2}$ retrieval are presented with error bars in Figure 6. These $\mathrm{NO}_{2}$ results have three distinct features. First, the values are consistently small; the mean is only $0.30 \mathrm{DU}$, and the retrieved values never once exceed 1 DU. Second, the monthly means (denoted by the dashed line) have a maximum value in January 2000 and a minimum value in July 1999. This hints at the possibility of a seasonal cycle, but the cycle cannot be confirmed because of the high level of noise and only 1 year of data. Third, as Figure 7 shows, there is minimal correlation between $\mathrm{NO}_{2}$ amounts and aerosol optical depth. While Alexandrov et al. [2002b] did acknowledge the trade-off between $\mathrm{NO}_{2}$ absorption and aerosol extinction at $415 \mathrm{~nm}$, it was hoped that the actual $\mathrm{NO}_{2}$ amount would fall within the range established using low and high effective variances in a single-mode aerosol size distribution. This turns out not to be the case.

[22] Even after redoing the single-mode aerosol retrievals using the gas amounts obtained with the full RSS resolution, inadequacies persist. Figure 8 depicts the results of the single-mode retrieval for the morning of 23 June, this time using the high-resolution $\mathrm{NO}_{2}$ retrieval. The $\mathrm{NO}_{2}$ seems to be measured adequately, but the aerosol optical depth has unacceptably large residuals in excess of 0.02 at both

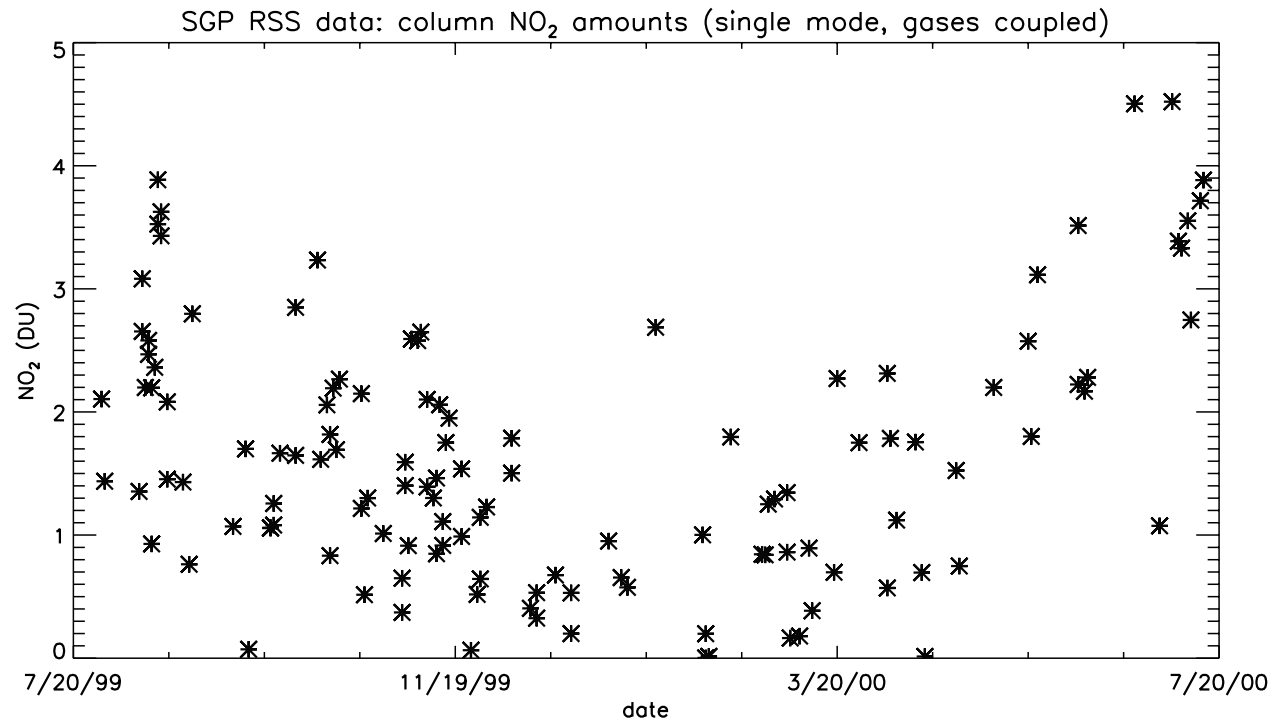

Figure 3. Plot of $\mathrm{NO}_{2}$ versus day, as determined by the coupled aerosol-gas retrieval, assuming a single-mode aerosol size distribution. Like the aerosols, $\mathrm{NO}_{2}$ values appear to follow a seasonal pattern with a summer maximum and a winter minimum. 


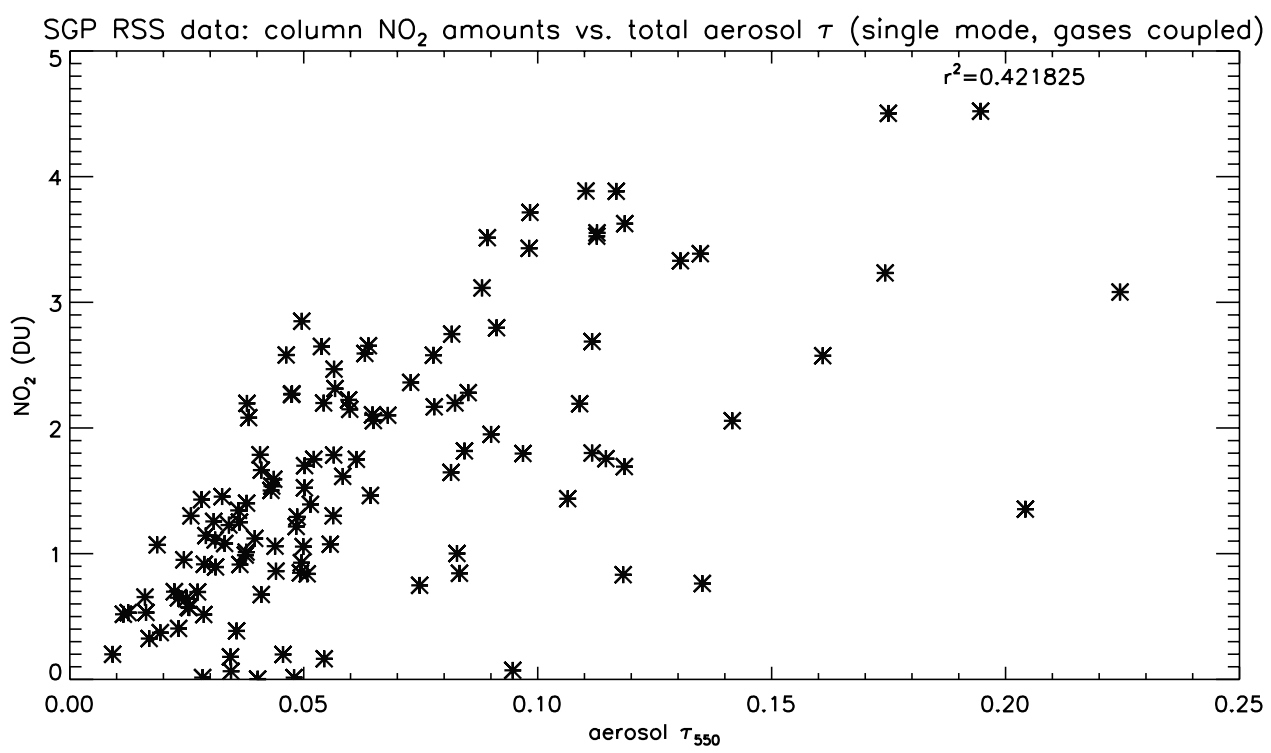

Figure 4. Plot of $\mathrm{NO}_{2}$ versus aerosol optical depth, as determined by the coupled aerosol-gas retrieval, assuming a single-mode aerosol size distribution, indicating that the two retrieved quantities are reasonably well correlated. This agrees with the results of Alexandrov et al. [2002a] but is shown in this paper to be misleading.

spectral extremes and, in the opposite direction, in the middle. A bimodal aerosol distribution would create exactly this kind of pattern in the residuals if the retrieval algorithm assumes a single-mode distribution. If the observation of Tanré et al. [1996] that the behavior of a bimodal aerosol distribution can be simulated well with a single distribution does indeed apply to satellite data, such a simulation proves not to be justified in RSS data when $\mathrm{NO}_{2}$ amounts are properly accounted for. For the SGP site, at least, all the criteria for establishing the inadequacy of the single-mode retrieval algorithm have therefore been met in the RSS data, confirming that the aerosol size distribution being observed is at least bimodal.

\subsection{Limits and Constraints on Retrievable Information}

[23] As the aerosol extinction in the data cannot be adequately described by a single-mode size distribution,

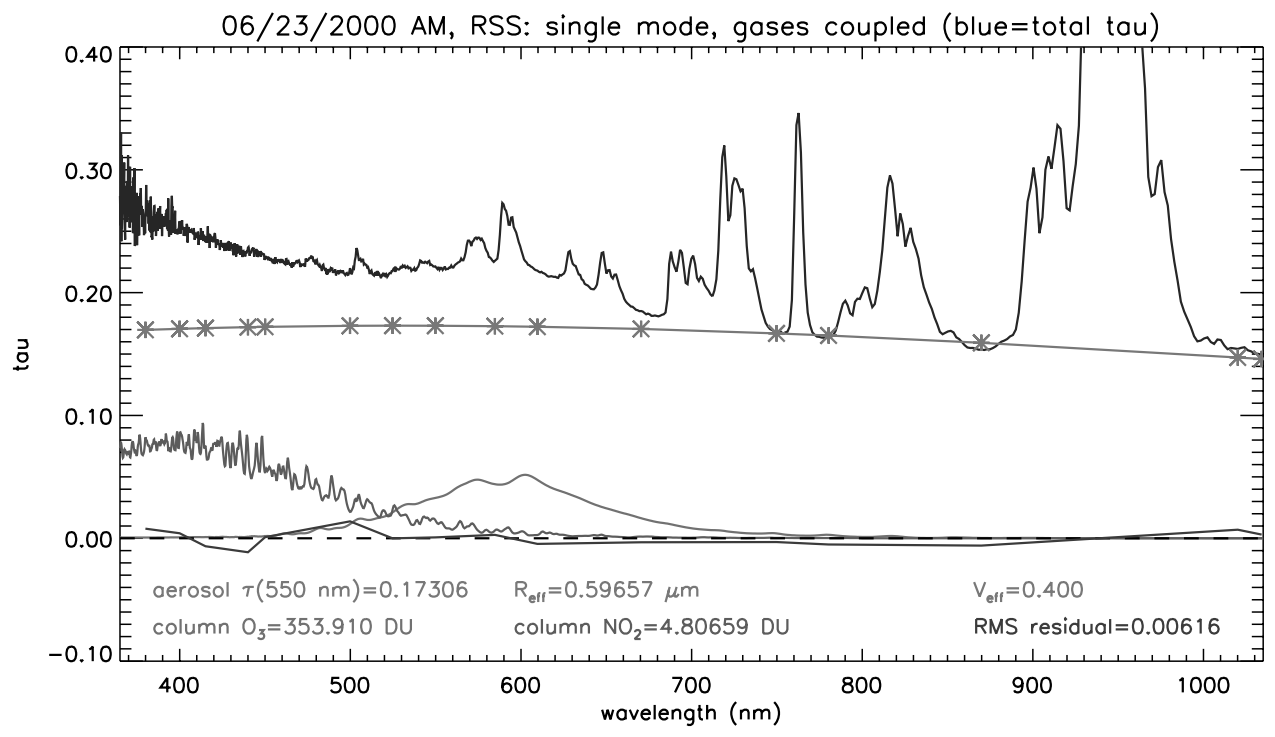

Figure 5. Plot of the contributions of $\mathrm{NO}_{2}$ (red), ozone (green), and aerosols (orange) to the total optical depth (blue) versus wavelength, as determined by the coupled aerosol-gas retrieval, assuming a singlemode aerosol size distribution. The day in question, 23 June 2000, has a particularly high aerosol optical depth value. The variation in $\mathrm{NO}_{2}$ extinction with wavelength for the retrieved value of 4.8 Dobson units (DU) $(1 \mathrm{DU}=0.001 \mathrm{~atm} \mathrm{~cm})$ is far larger than the variation of the total optical depth, indicating that the single-mode retrieval badly overestimates the column $\mathrm{NO}_{2}$ amount. See color version of this figure in the HTML. 


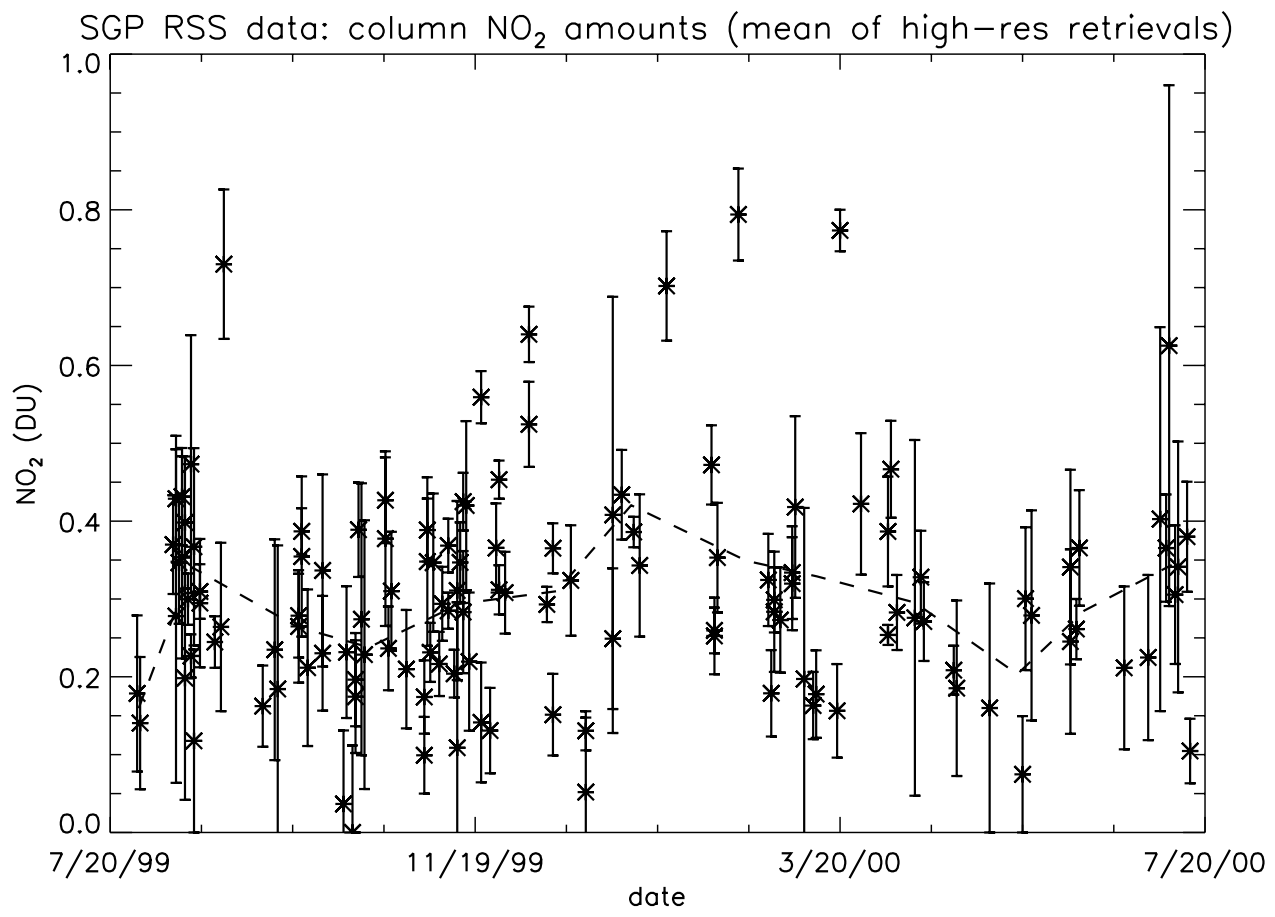

Figure 6. Results of the high-resolution $\mathrm{NO}_{2}$ retrievals of rotating shadowband spectroradiometer (RSS) data along with error bars. These results are much smaller than those plotted in Figure 3; the mean is only $0.30 \mathrm{DU}$, and none of the retrieved values exceed $1 \mathrm{DU}$. The dotted line plots the monthly mean values. The maximum monthly mean in January and minimum in July suggest the possibility of a seasonal pattern, but the evidence is far from conclusive.

the question then becomes what aerosol properties in a bimodal distribution can be retrieved, given an incomplete amount of information. Table 2 presents the mean values over the data sets of retrieved quantities for bimodal retrievals for both simultaneous and high-resolution retrievals of gas amounts. For the sake of comparison, the mean values for the single-mode aerosol, high-resolution gas retrievals are used as well. Simply switching from a unimodal to a bimodal aerosol size distribution does improve, at least on average, the gas results, especially for $\mathrm{NO}_{2}$. However, attempting to retrieve the optical depth, effective radius, and effective variance for both a coarse and a fine aerosol mode produces misleading results, even in a 1000-channel device like the RSS. The retrieved values for the fine-mode effective radius over the full data set, in the case where the gases are retrieved using high resolution, are plotted versus the simultaneously retrieved values for the fine-mode effective variance in Figure 9. It is clear from this graph that

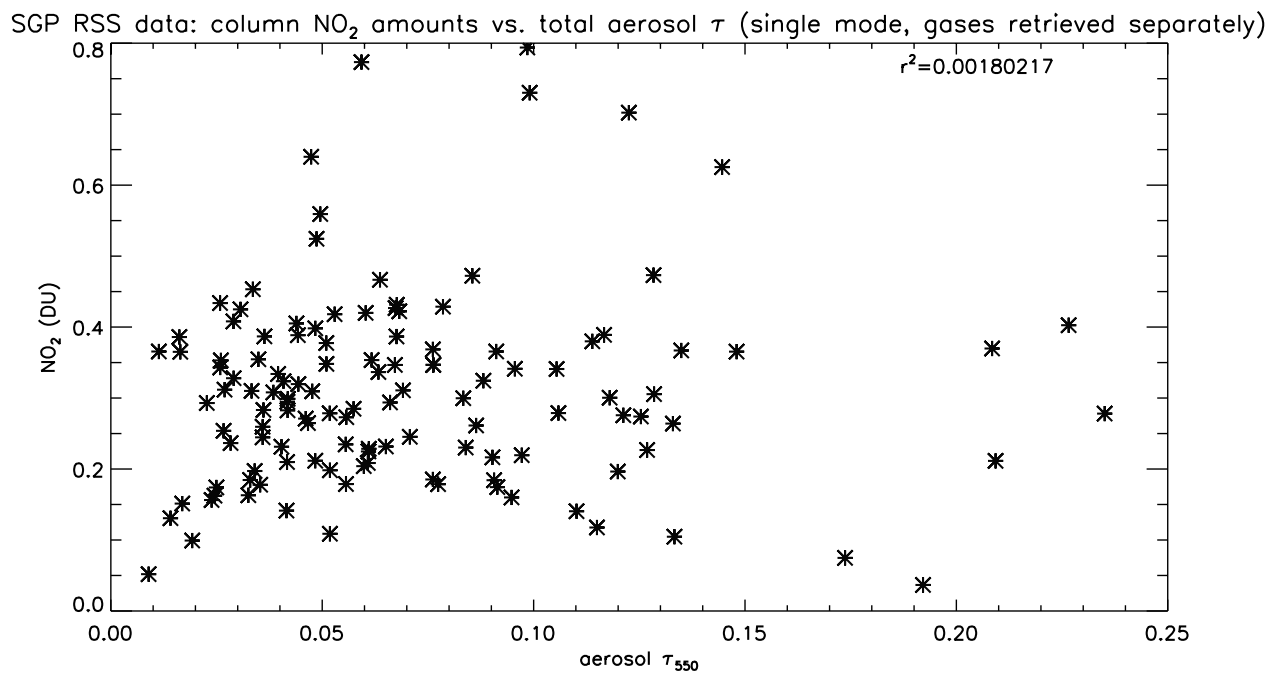

Figure 7. Plot of the $\mathrm{NO}_{2}$ amounts retrieved with high resolution versus aerosol optical depth. This time the correlation between the two quantities completely vanishes. 


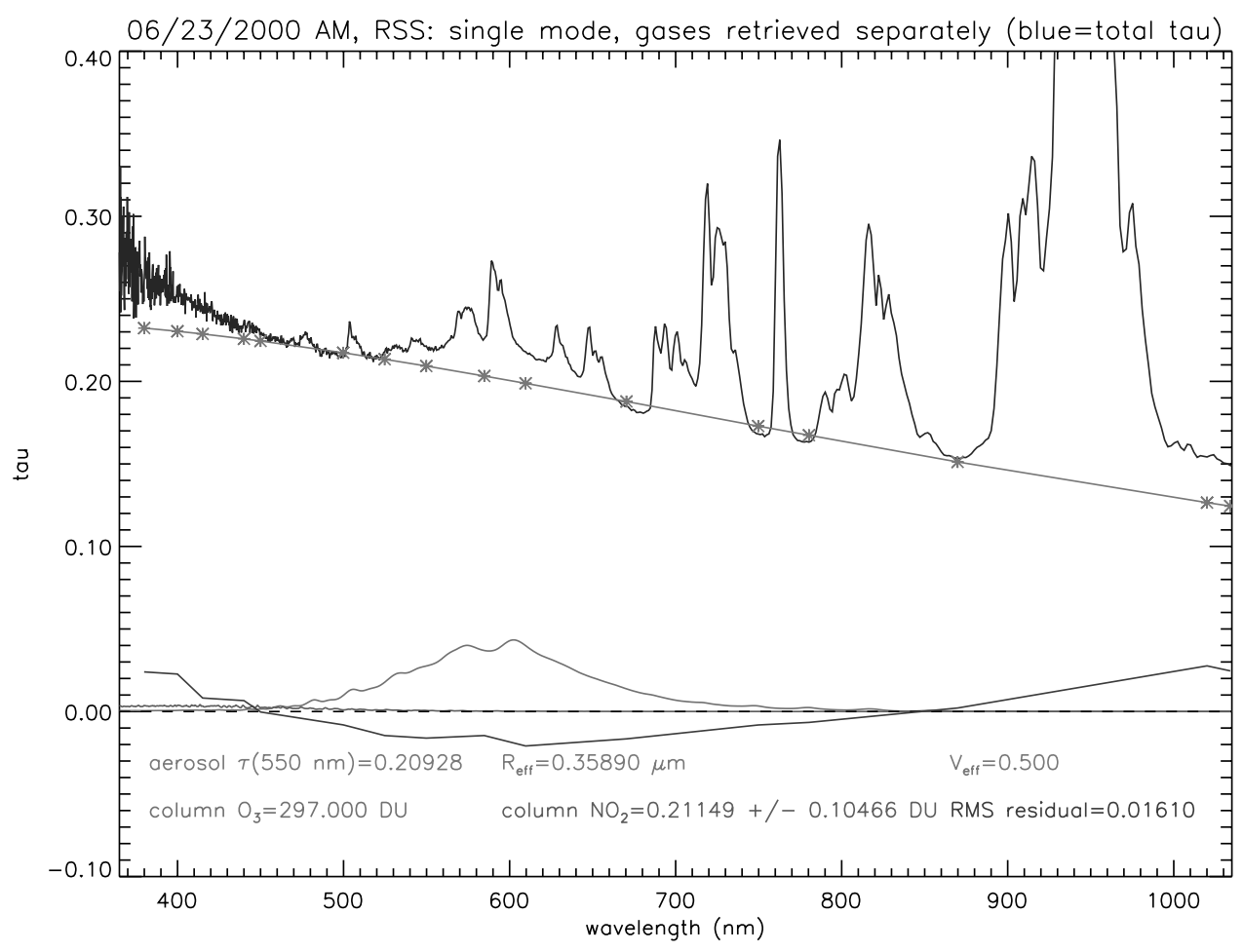

Figure 8. Plot of the contributions of $\mathrm{NO}_{2}$ (red), ozone (green), and aerosols (orange) to the total optical depth (blue) versus wavelength, when the gases are determined with high resolution and the aerosol size distribution is assumed to be unimodal. The residual optical depth is positive and very high at either end of the wavelength range and is negative in the middle. This result is fully consistent with an aerosol size distribution that is, in reality, either bimodal or multimodal. See color version of this figure in the HTML.

the two quantities are not being retrieved independently from each other, as the values for the effective radius tend to be low when the effective variance is increased beyond 0.1 .

[24] Retrieving specific qualities of the coarse-mode size distribution results in even more complications. To show this, the retrieval is performed for every combination of coarse- and fine-mode effective radius values, in increments of $0.01 \mu \mathrm{m}$ for the fine mode and $0.1 \mu \mathrm{m}$ for the coarse mode, for the morning of 23 June 2000. The RMS residual optical depth is calculated from the retrieval results for each combination. The lower the RMS residual, the more closely the retrieval results fit the optical depth data. Only effective variance values of 0.1 were considered for this plot. Figure 10 presents a contour plot of the RMS residual optical depth values, plotted versus the coarse-mode effective radius in the vertical and the fine-mode effective radius in the horizontal. The contours show a series of relative minimum residual values. With one exception these minima fall within $0.01 \mu \mathrm{m}$ of each other on the fine-mode axis, but they cover the full scale for the coarse mode. This indicates that the fine-mode effective radius can be reasonably constrained but the coarse-mode effective radius cannot.

[25] To understand why even a high-resolution device such as the RSS does not contain enough aerosol information to uniquely constrain a bimodal aerosol size distribution, it is

Table 2. Mean Retrieved Values for the Bimodal RSS Retrievals ${ }^{\mathrm{a}}$

\begin{tabular}{|c|c|c|c|c|c|c|c|c|c|}
\hline & $\begin{array}{c}\text { Mean } \\
\text { Fine-Mode } \tau\end{array}$ & $\begin{array}{c}\text { Mean } \\
\text { Fine-Mode } \\
r_{\text {eff }}, \mu \mathrm{m}\end{array}$ & $\begin{array}{c}\text { Dominant } \\
\text { Fine-Mode } \\
v_{\text {eff }} b\end{array}$ & $\begin{array}{c}\text { Mean } \\
\text { Coarse-Mode } \\
\tau \\
\end{array}$ & $\begin{array}{c}\text { Mean } \\
\text { Coarse-Mode } \\
r_{\text {eff }}, \mu \mathrm{m}\end{array}$ & $\begin{array}{c}\text { Dominant } \\
\text { Coarse-Mode } \\
v_{\text {eff }} \\
\end{array}$ & $\begin{array}{c}\text { Mean } \\
\mathrm{NO}_{2}, \mathrm{DU}\end{array}$ & $\begin{array}{c}\text { Mean } \\
\text { Ozone, DU }\end{array}$ & $\begin{array}{c}\text { RMS } \\
\text { Residual } \tau \\
\end{array}$ \\
\hline $\begin{array}{l}\text { RSS bimodal, } \\
\text { gases separate }\end{array}$ & 0.048 & 0.168 & $0.1(77.2 \%)$ & 0.019 & 1.20 & $0.1(86.6 \%)$ & $0.30 \pm 0.08$ & 279 & 0.00160 \\
\hline $\begin{array}{l}\text { RSS bimodal, } \\
\text { gases coupled }\end{array}$ & 0.048 & 0.170 & $0.1(42.5 \%)$ & 0.018 & 1.48 & $0.1(78.0 \%)$ & 0.51 & 270 & 0.00145 \\
\hline $\begin{array}{l}\text { RSS bimodal, } \\
\text { established limits }\end{array}$ & $0.046 \pm 0.004$ & $0.178 \pm 0.017$ & 0.1 & $0.020 \pm 0.004$ & $2.5 \pm 1.5$ & 0.1 & $0.30 \pm 0.08$ & 279 & 0.00171 \\
\hline $\begin{array}{l}\text { RSS single mode, } \\
\text { gases coupled }\end{array}$ & 0.064 & 0.290 & $0.5(87.4 \%)$ & $\ldots$ & $\cdots$ & $\cdots$ & 1.60 & 262 & 0.00289 \\
\hline
\end{tabular}

${ }^{\mathrm{a}}$ For the sake of comparison the single-mode retrieval with the high-resolution gas values is also included. The mean values for the bimodal, coupled aerosol/gas retrieval agree well with the means using the high-resolution gas values, which are considered the better overall results. When the coarse-mode effective radius is allowed to vary by a large amount, the resulting margin of error in the other retrieved quantities is, on average, not all that large. The mean value for the fine-mode effective radius in this case is larger than for the other two, though, because the effective variance is set to a low value.

${ }^{b}$ Value in parentheses is the percentage of time the dominant effective variance is retrieved over the course of the data set. 


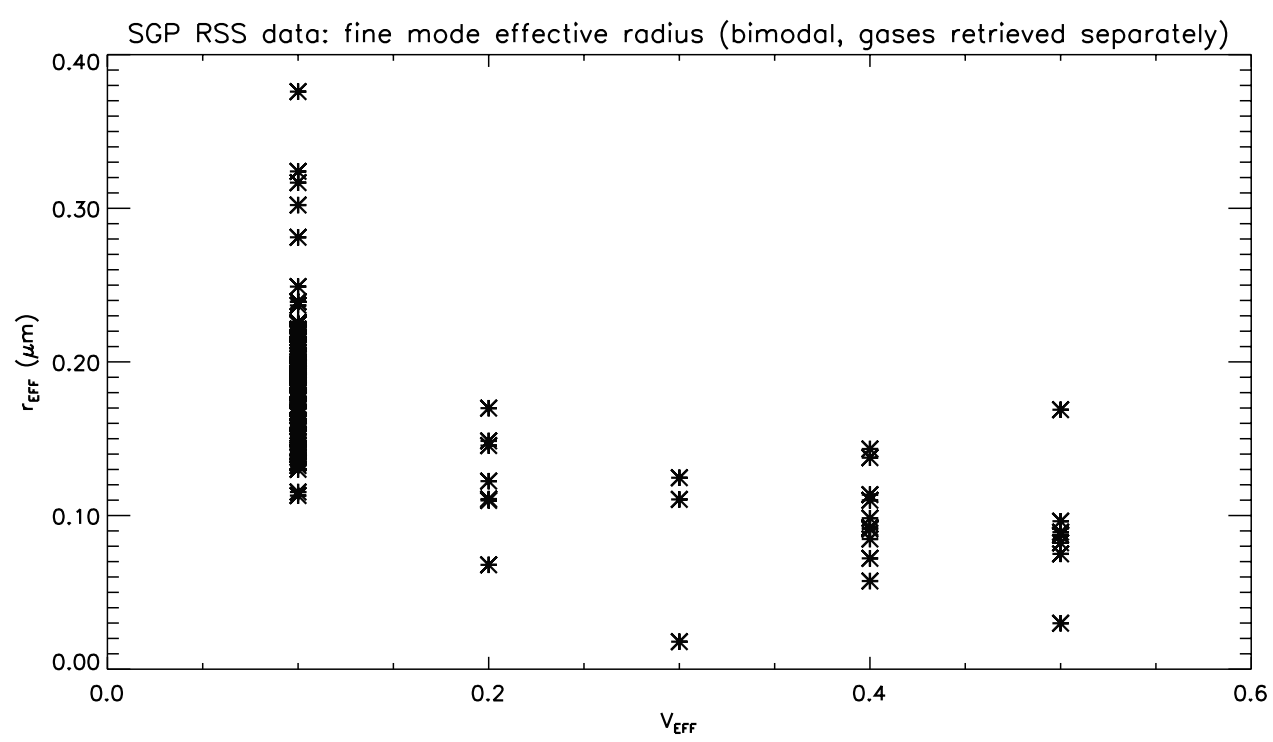

Figure 9. Plot of the fine-mode effective radius versus the fine-mode effective variance in the bimodal RSS retrievals. The two quantities appear to be interdependent on each other, as the high variance values almost always correspond to low radius values. This result reflects the limited amount of aerosol information contained within the data.

necessary to look at the Mie scattering results. Figure 11 shows the Mie extinction curves, normalized at $550 \mathrm{~nm}$, for six different fine-mode radius/variance combinations. The effective radius is steadily increased while the variance is decreased. The wavelength range in this plot is extended beyond the range of the RSS both into the near infrared and ultraviolet. The curves are barely discernible from each other, except when the wavelength approaches $300 \mathrm{~nm}$. For the coarse mode, Figure 12 shows that the effective radius cannot be uniquely retrieved, and it also shows what additional spectral information would be needed to better constrain the coarse-mode effective radius. The Mie extinction curves are shown for two coarse-mode size distributions, one representing the average values for the effective radius and variance retrieved from the RSS data and the other representing the averages obtained using the CIMEL almucantar sky

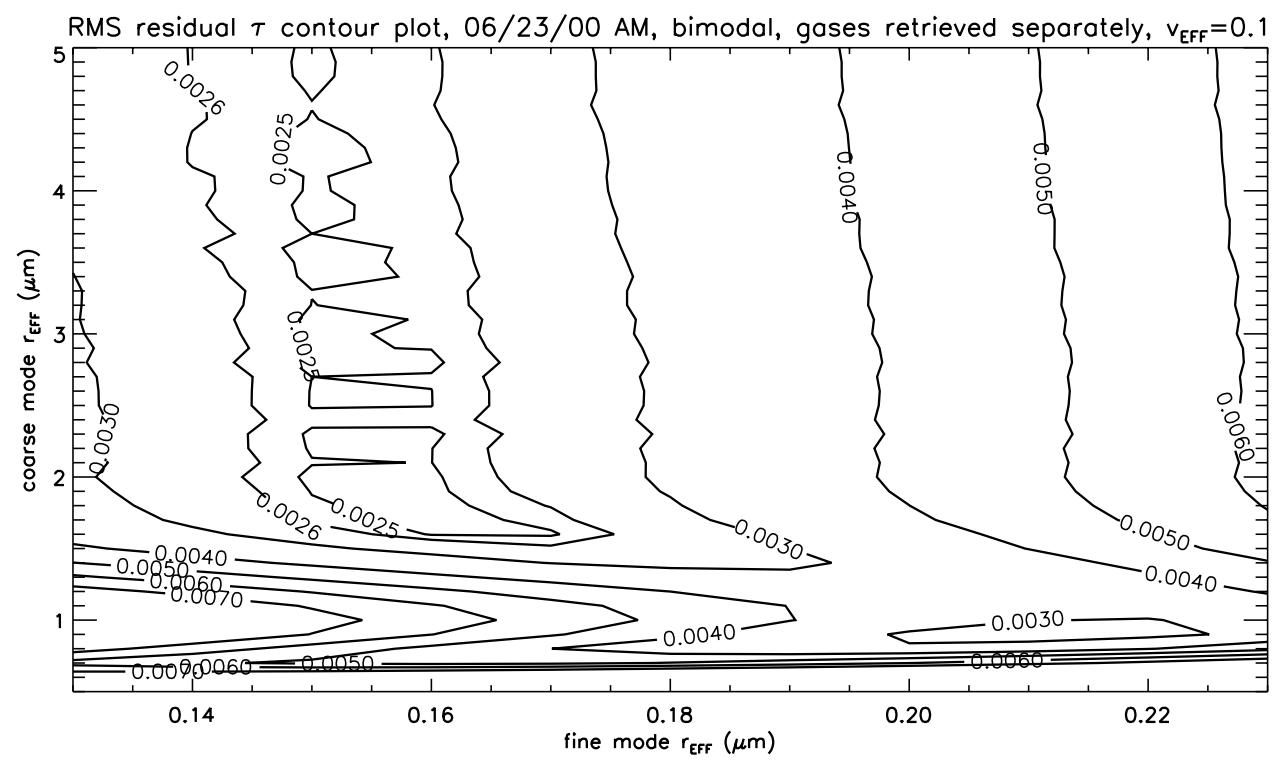

Figure 10. Contour plot of the residual optical depth values for the bimodal retrieval of the RSS data on the morning of 23 June 2000. The $y$ axis is the coarse-mode effective radius, and the $x$ axis is the finemode effective radius, with both effective variance values set to 0.1 . The contour plot shows a series of convergence points across the range of examined values for the coarse-mode effective radius. The finemode effective radius at these convergence points remains consistent, with one exception. This indicates that the coarse-mode effective radius cannot be specifically defined in the RSS retrievals, while the finemode effective radius can. 


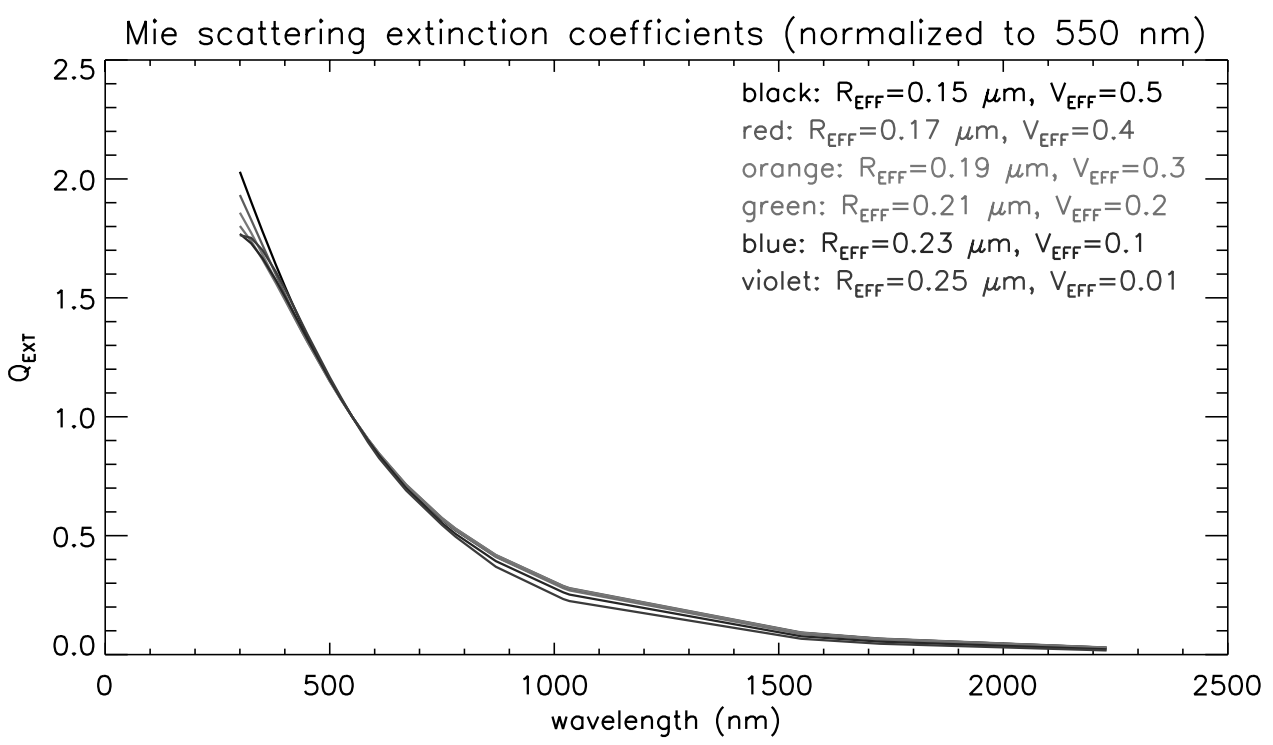

Figure 11. Comparative plot of the Mie scattering extinction curves, normalized to 1 at $550 \mathrm{~nm}$, versus wavelength for a series of different fine-mode effective radius/effective variance combinations. The plot clearly shows how hard it is to distinguish between a given combination and one with a slightly lower effective radius and a slightly higher effective variance. The curves only become distinct as the wavelength approaches $300 \mathrm{~nm}$, with the lowest effective radius producing the highest relative Mie scattering coefficient. See color version of this figure in the HTML.

radiances and spectral aerosol optical depth data obtained during the same time period from the CART site located at SGP. Although quite different physically, the two distributions have nearly identical Mie curves at short wavelengths. The curves start to diverge at the $870 \mathrm{~nm}$ channel but only become very clearly different well into the near infrared beyond the spectral range of the RSS or CIMEL. This indicates that it will likely take monitoring devices with broader wavelength ranges, especially extending into the near infrared, to clearly define the coarse mode beyond an

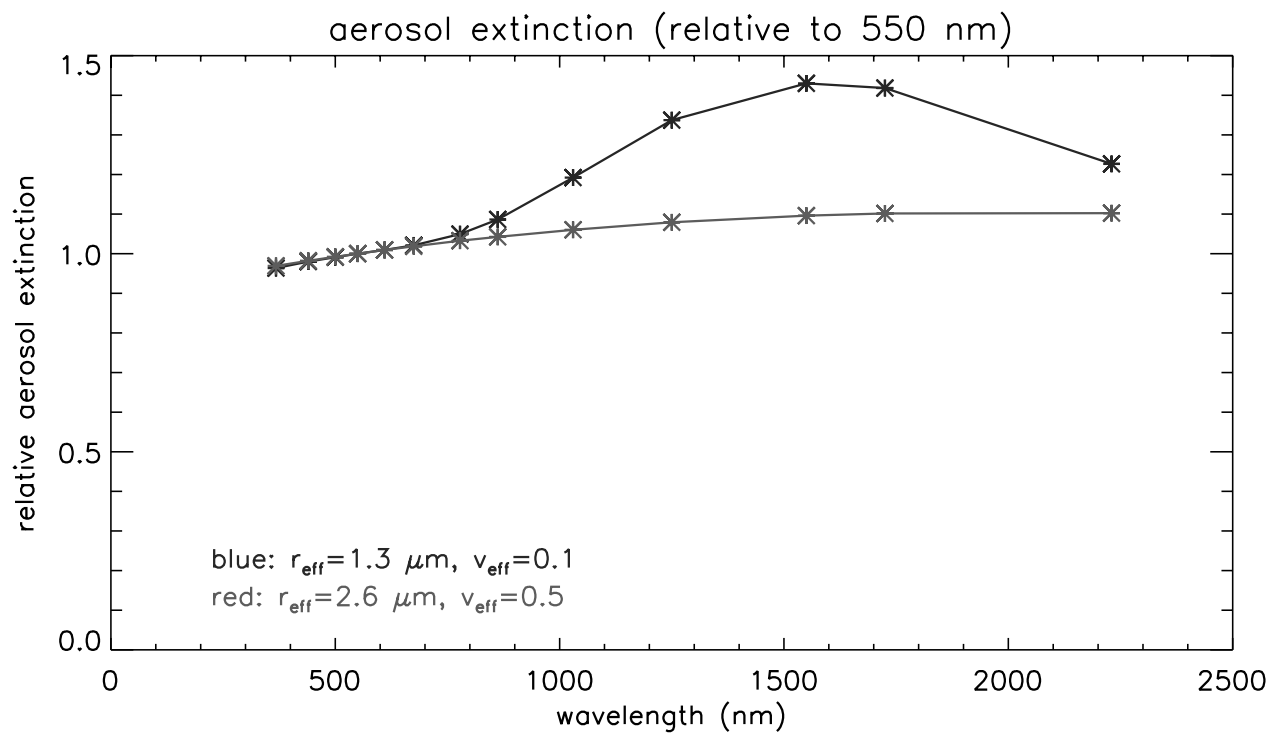

Figure 12. Comparative plot of the Mie scattering extinction curves, normalized to 1 at $550 \mathrm{~nm}$, versus wavelength for a pair of very different coarse-mode effective radius/effective variance combinations. The two combinations (the top curve has an effective radius of $1.3 \mu \mathrm{m}$ and an effective variance of 0.1 , and the bottom curve has an effective radius of $2.6 \mu \mathrm{m}$ and an effective variance of 0.5 ) are not distinguishable at all from each other until $870 \mathrm{~nm}$ and are even then only clearly distinguishable beyond the wavelength range used by the RSS. This explains the inherent difficulty in defining the coarse-mode effective radius and indicates that extending the wavelength range of devices more deeply into the infrared would enable more precise retrievals. See color version of this figure in the HTML. 


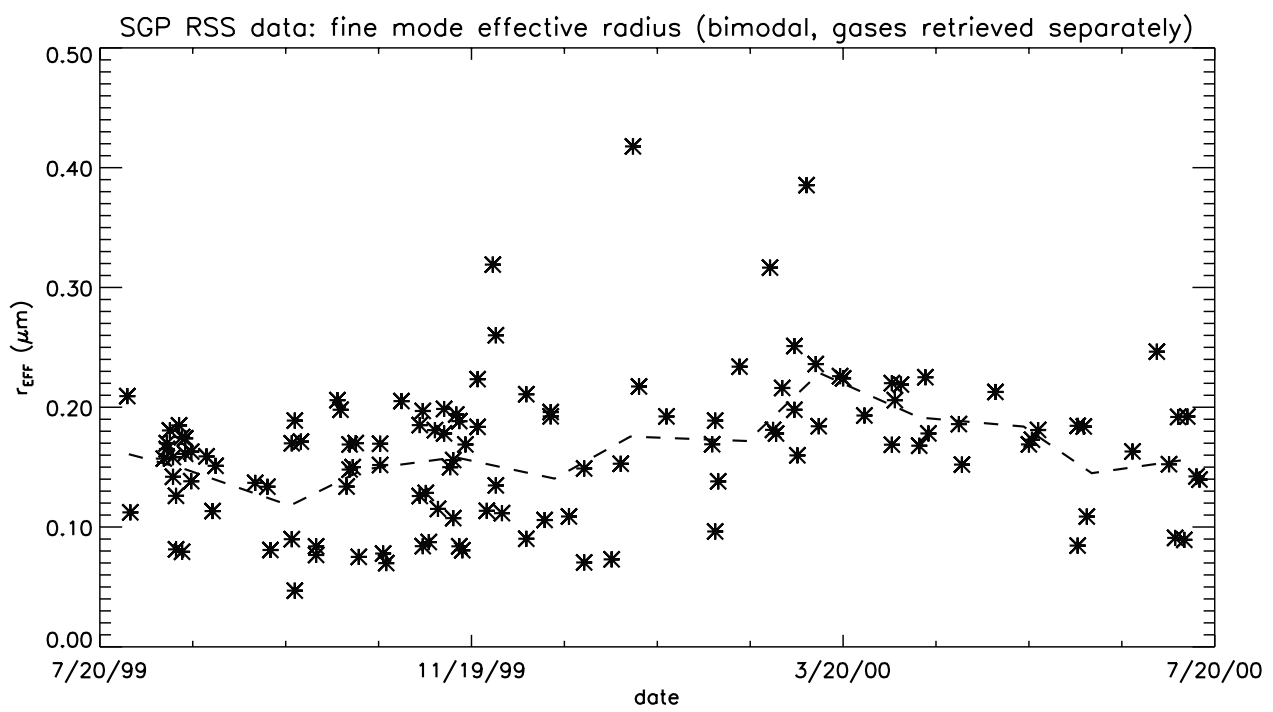

Figure 13. Plot of the fine-mode effective radius values without constraining the effective variance. The dashed line shows the monthly means and hints at the possibility of an annual cycle with a peak in March and a minimum in September. However, the cycle is rendered ambiguous by the broad range of retrieved radius values.

optical depth value when only spectral aerosol optical depth data have been utilized in the retrieval.

\subsection{Retrievals Within the Established Limits}

[26] It would therefore appear that an aerosol retrieval algorithm for devices with wavelength ranges similar to that of the RSS can reasonably attempt to retrieve only the fineand coarse-mode optical depths and the fine-mode effective radius if only direct beam optical depth data are used. For the effective variance values and the coarse-mode effective radius, reasonable assumptions need to be made. Effective variance values of 0.1 were retrieved with the greatest frequency in the full retrieval for both aerosol modes ( $77.2 \%$ for the coarse mode and $86.6 \%$ for the fine mode), and an analysis by Gianelli [2004] indicated that the almucantar-retrieved size distributions [Dubovik and King, 2000] obtained from the CIMEL data at the SGP site showed similar results at least for the fine-mode effective radius (a rounded value of 0.1 for the fine-mode effective variance was calculated $62.4 \%$ of the time). The accuracy of these values cannot be guaranteed without validation from a more exhaustive analysis of aerosol size distributions. However, assumed variances of 0.1 will suffice to constrain the results so that as clear an analysis as possible can be made. By contrast, the margin of error for the coarse-mode effective radius is too large to justify using one specific value, so the retrievals are performed using values of 1.0 , 2.5 , and $4.0 \mu \mathrm{m}$. For each quantity the mean value for the three retrievals is output as the retrieved value, while the highest and lowest values set the boundaries for the error bars.

[27] Figures 13 and 14 show how attempting to retrieve too much information can mask potentially significant results. In Figure 13 the values of the fine-mode effective radius, retrieved by the first bimodal method, are plotted versus day. The dashed line shows the monthly means, which hints at the possibility of a seasonal pattern in the data. However, the large spread in effective radius values, caused at least in part by the simultaneous retrieval of effective variance values, makes this result somewhat ambiguous. For this retrieval the fine-mode effective radius has a mean value of $0.168 \mu \mathrm{m}$ and a standard deviation of $0.059 \mu \mathrm{m}$. The results of the new retrieval, with the information limits kept in mind, are presented in Figure 14, with error bars included. As expected from the contour plot of Figure 10, most days show very little variation in the value of the finemode effective radius. The margin of error does not, on average, exceed $0.02 \mu \mathrm{m}$; roughly half of this error range comes from the error range of $\mathrm{NO}_{2}$ in the DOAS retrieval, and the other half comes from the indeterminacy of the coarse aerosol mode. More significantly, despite an increase in the mean to $0.178 \mu \mathrm{m}$ the standard deviation is reduced to $0.043 \mu \mathrm{m}$, enabling the seasonal variation to appear much more clearly within the data. Other than a handful of days where the retrieved values exceed the general pattern, the peak in the cycle appears to occur in March, and the minimum appears to occur in September. This shows some qualitative, if inconclusive, agreement not only with the results of the Holben et al. [2001] aerosol climatology for the CIMEL at the SGP site, obtained by calculating the Angstrom coefficients for the optical depth data between 1994 and 1999, but also with values of the fine-mode effective radius calculated from the size distributions derived from the almucantar and direct sky data from this CIMEL [Gianelli, 2004]. While the samples are too limited to draw definitive conclusions, the results do indicate that the possibility of a seasonal pattern in aerosol size distributions, at least at the SGP site, needs to be examined more closely over a longer span of time. The mean values for the RSS retrieval, along with their margins of error, are also included in Table 2. Predictably, with a small fine-mode variance the mean effective radius has increased somewhat. It is important to establish whether 0.1 is a reasonably accurate value to assume for the fine- 


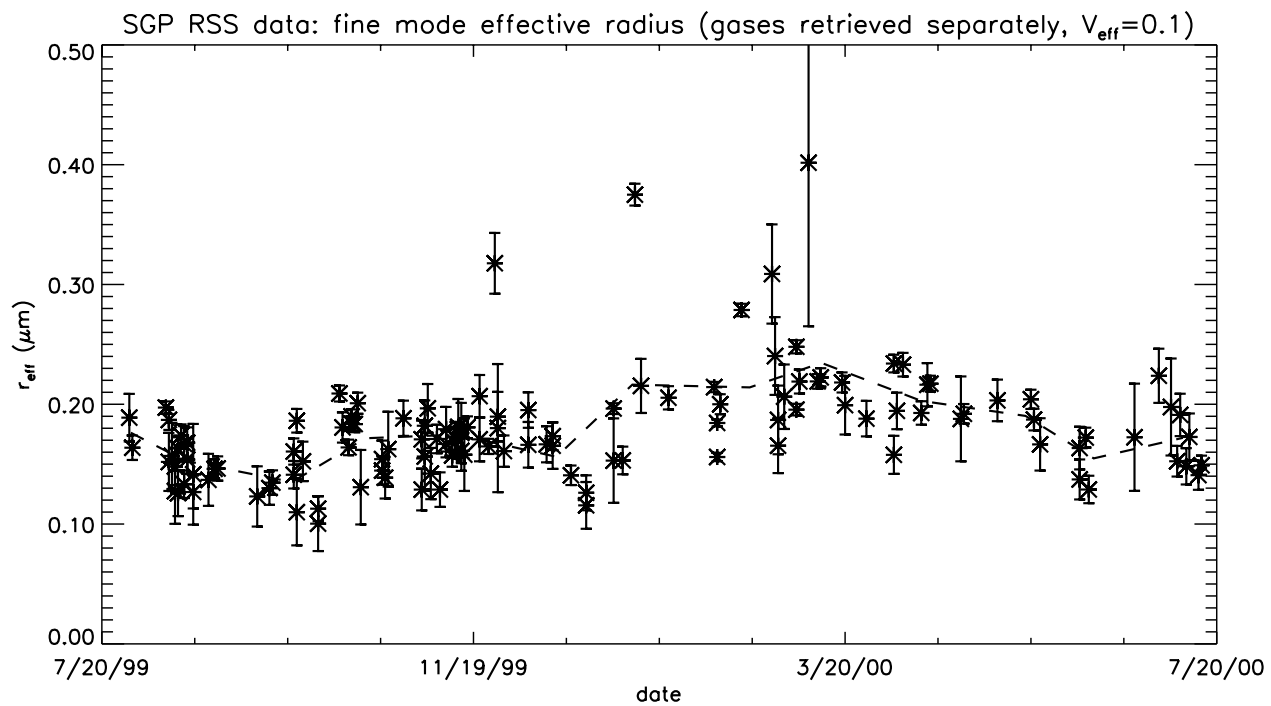

Figure 14. Same plot as Figure 13, with two differences. First, the fine-mode effective variance is constrained to equal 0.1 . Second, the coarse-mode effective radius is allowed to vary broadly, and error bars represent the range of possible values. The dashed line shows the same annual cycle as before, but now the cycle emerges much more clearly in the scatterplot. In general, the days where the error bar is largest correspond to days with a high coarse-mode optical depth. The bimodal retrievals performed using high-resolution gas amounts and allowing for margins of error due to the indeterminacy of the coarsemode effective radius are considered to be the best retrievals for the RSS data.

mode effective variance because the retrieved particle size depends significantly on it. Furthermore, the possibility that the fine-mode effective variance is not static also needs to be considered; for example, Colarco et al. [2004] have shown that the optical properties of a smoke cloud change significantly as the cloud ages, both in terms of the mean size and the width of the distribution.

[28] The fine- and coarse-mode optical depths, along with error bars, are plotted versus day in Figures 15 and 16, respectively. Both graphs show a seasonal cycle, with maxima in the summer and minima in the winter. The fine-mode optical depth shows particularly high values in early August and early October 1999. By contrast, two particularly high coarse-mode optical depth days occurred on 23 June and 5 July 2000. The most significant element of Figure 16, though, is the strong dependence of the size of the error bars on the coarse-mode optical depth. This indicates that on most days, when the coarse-mode optical depth is low, measurement errors caused by the inability to determine the size distribution of the coarse mode are not

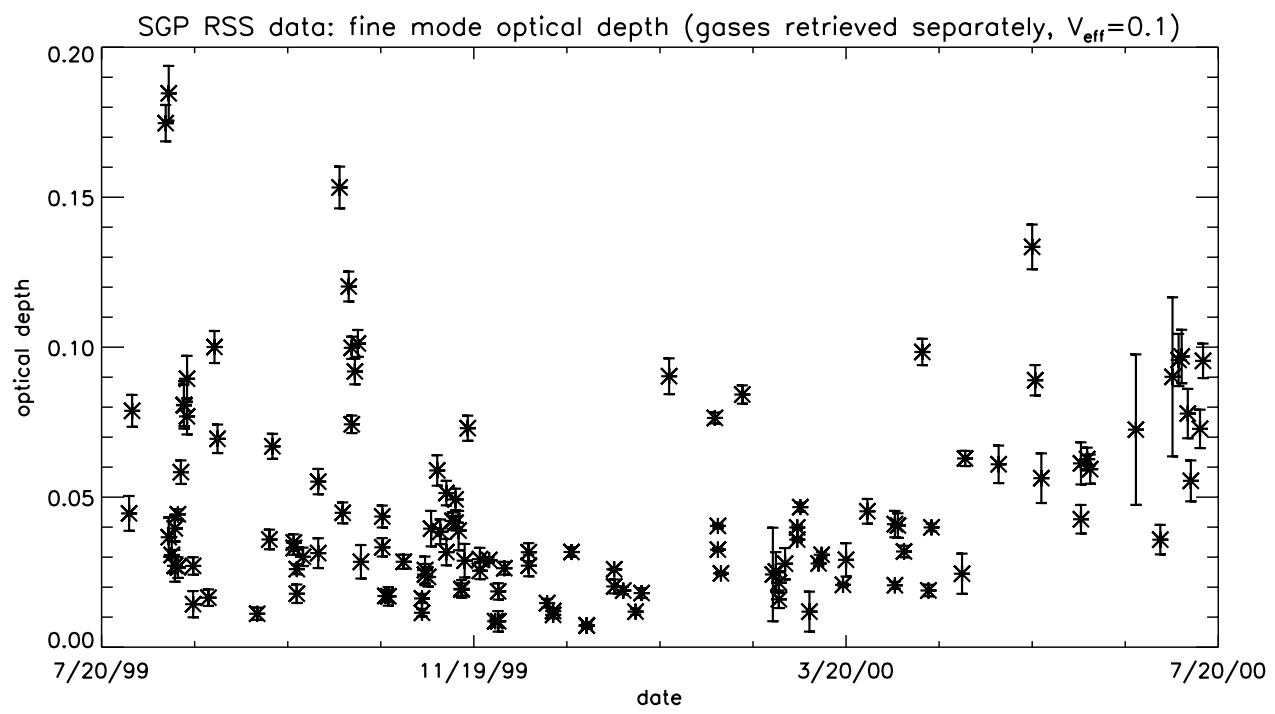

Figure 15. Plot of the retrieved fine-mode optical depth versus day, with error bars. The high-optical depth events in August and October of 1999 seem to have been dominated by fine-mode aerosol particles. 


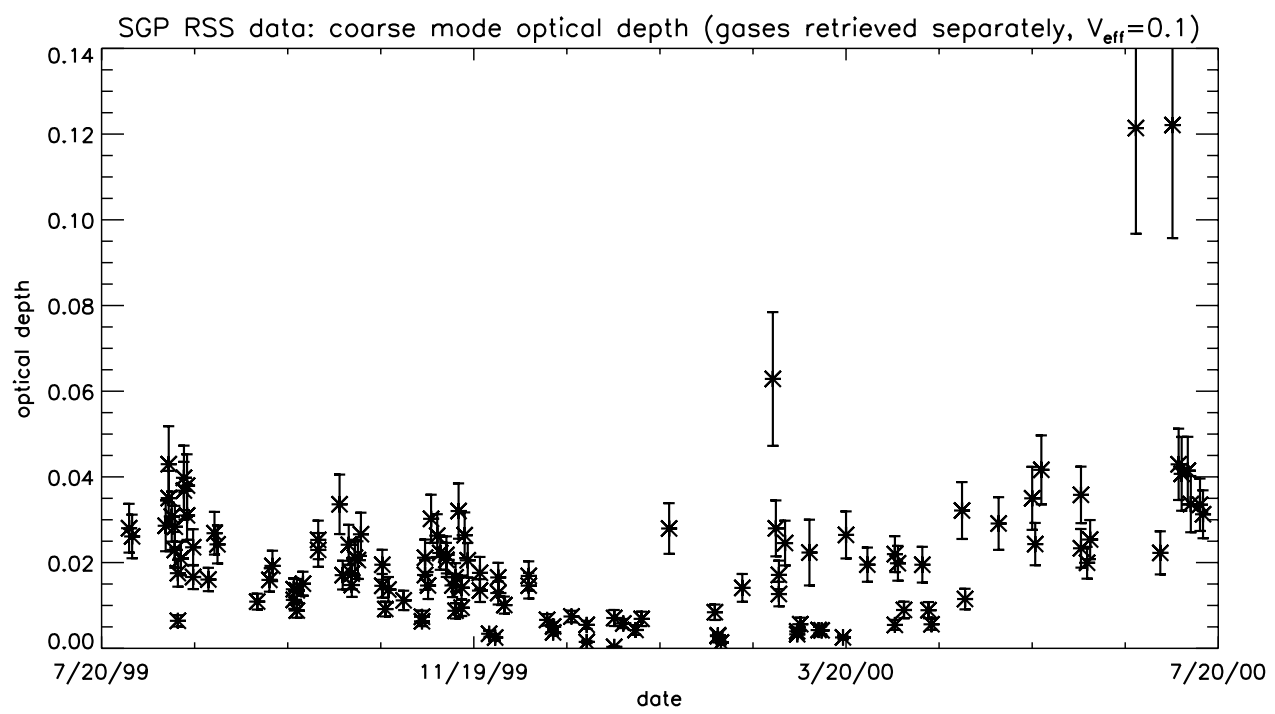

Figure 16. Plot of the retrieved coarse-mode optical depth versus day, with error bars. Predictably, the error bars due to the indefinite coarse-mode effective radius are largest when the coarse-mode optical depth is highest. Like the fine mode the coarse mode has its highest values in summer and lowest values in winter. The particularly high days in the data set occur on 23 June and 5 July 2000.

significant. However, when the coarse-mode optical depth becomes large, the indeterminacy in all the retrieved quantities increases.

\section{Using the RSS to Improve the MFRSR}

[29] Wavelengths corresponding to the five nonwater filters of the MFRSR can be isolated from the rest of the RSS data for use in an "MFRSR equivalent" retrieval. The retrieval algorithm devised for 16 channels needs to be modified only slightly to accommodate the smaller number of channels. Assuming that the 16-channel retrieval produces better results, the "equivalent" retrieval will show how much error is introduced just by reducing the number of wavelengths. The primary benefit to this approach is that it eliminates differences in optical depth measurements at the same wavelength, such as those that would arise from calibration differences between different devices, as a source of discrepancy in retrieval comparisons. In addition, the higher resolution of the RSS channels eliminates the possibility of extraneous gas absorption adding to the total optical depth in a given channel.

[30] Furthermore, the MFRSR equivalent approach can be combined with the broader spectral range of the RSS to see if a different set of wavelengths would improve the accuracy of MFRSR retrievals. The retrieval algorithm can be altered simply by replacing the $670 \mathrm{~nm}$ channel with one at 375 or $1034 \mathrm{~nm}$ to see if either or both of these wavelengths improve the agreement with the 16-channel retrieval. In addition, since the MFRSR contains an additional "open" filter, the possibility of replacing this filter and the $670 \mathrm{~nm}$ filter with ones at 375 and $1034 \mathrm{~nm}$ can also be investigated. As filters with these approximate wavelengths already exist, making such an alteration to existing MFRSR devices would be minor and inexpensive. Working with a channel around $1034 \mathrm{~nm}$ requires an additional source of error to be considered, though. $\mathrm{O}_{2}-\mathrm{O}_{2}$ absorption in that region adds $\sim 0.002$ to the total optical depth, as determined from the measurements of Greenblatt et al. [1990].

[31] In all these retrievals the bimodal aerosol size distribution is assumed. The coarse-mode effective radius is given a large margin of error as before, and error bars are likewise calculated for the retrieved quantities. Coarse- and fine-mode optical depths, fine-mode effective radius, and ozone are retrieved in all cases. In the first set of three cases, nitrogen dioxide is retrieved as well. For the next set the $\mathrm{NO}_{2}$ values retrieved by high-resolution are assumed in the retrieval to determine if the ideal wavelength combination changes when $\mathrm{NO}_{2}$ can be measured by independent means. Finally, the retrieval is done with $\mathrm{NO}_{2}$ given the indeterminate value of $0.3 \pm 0.3 \mathrm{DU}$, corresponding roughly to the mean and twice the standard deviation of the $\mathrm{NO}_{2}$ values retrieved with high-resolution. If it turns out that $\mathrm{NO}_{2}$ cannot be measured with precision, it is important to acknowledge the degree of error that will be introduced as a result. The mean values of all these retrievals are presented in Table 3, with the means of the full RSS retrieval included for comparison.

\subsection{Results With $\mathrm{NO}_{2}$ Included in the Retrieval}

[32] From the first set of retrievals, where nitrogen dioxide is retrieved along with ozone and the aerosol information, it becomes clear that replacing the $670 \mathrm{~nm}$ channel with one that broadens the wavelength range on either end will improve the quality of the retrieval. The coarse- and fine-mode aerosol optical depths, the fine-mode effective radius, and ozone all show improved agreement in their mean values with those of the full RSS retrievals when either the $375 \mathrm{~nm}$ channel or the $1034 \mathrm{~nm}$ channel is substituted for the channel at $670 \mathrm{~nm}$. This happens because the amount of information obtainable from data produced by a given device is mostly a function of the spectral range of the measurements. As for which channel is ultimately better, that appears to depend on which quantities are the most important to know. Clearly, including the $1034 \mathrm{~nm}$ 
Table 3. Mean Retrieved Values for the Bimodal, Five-Channel RSS Retrievals Along With Their Mean Margins of Error ${ }^{\mathrm{a}}$

\begin{tabular}{|c|c|c|c|c|c|c|}
\hline & $\begin{array}{c}\text { Mean } \\
\text { Fine-Mode } \tau\end{array}$ & $\begin{array}{c}\text { Mean } \\
\text { Fine-Mode } \\
r_{\text {eff }}, \mu \mathrm{m} \\
\end{array}$ & $\begin{array}{c}\text { Mean } \\
\text { Coarse-Mode } \tau\end{array}$ & $\begin{array}{c}\text { Mean } \\
\mathrm{NO}_{2}, \mathrm{DU} \\
\end{array}$ & $\begin{array}{c}\text { Mean } \\
\text { Ozone, DU }\end{array}$ & $\begin{array}{c}\text { RMS } \\
\text { Residual } \tau \\
\end{array}$ \\
\hline Sixteen channels, high-resolution gases & $0.046 \pm 0.004$ & $0.178 \pm 0.017$ & $0.020 \pm 0.004$ & $0.30 \pm 0.08$ & 279 & 0.00171 \\
\hline Five channels, with $670 \mathrm{~nm}$ & $0.054 \pm 0.003$ & $0.233 \pm 0.013$ & $0.013 \pm 0.004$ & $0.68 \pm 0.12$ & $260 \pm 0$ & 0.00007 \\
\hline Five channels, with $375 \mathrm{~nm}$ & $0.052 \pm 0.002$ & $0.205 \pm 0.004$ & $0.014 \pm 0.002$ & $0.56 \pm 0.01$ & $265 \pm 3$ & 0.00039 \\
\hline Five channels, with $1034 \mathrm{~nm}$ & $0.046 \pm 0.004$ & $0.152 \pm 0.011$ & $0.021 \pm 0.004$ & $0.04 \pm 0.01$ & $271 \pm 4$ & 0.00071 \\
\hline Six channels & $0.048 \pm 0.003$ & $0.183 \pm 0.006$ & $0.019 \pm 0.003$ & $0.41 \pm 0.03$ & $268 \pm 4$ & 0.00119 \\
\hline $670 \mathrm{~nm}$, high-resolution $\mathrm{NO}_{2}$ & $0.051 \pm 0.003$ & $0.202 \pm 0.015$ & $0.016 \pm 0.004$ & $0.30 \pm 0.08$ & $263 \pm 2$ & 0.00033 \\
\hline $375 \mathrm{~nm}$, high-resolution $\mathrm{NO}_{2}$ & $0.052 \pm 0.003$ & $0.193 \pm 0.010$ & $0.016 \pm 0.003$ & $0.30 \pm 0.08$ & $263 \pm 5$ & 0.00097 \\
\hline $1034 \mathrm{~nm}$, high-resolution $\mathrm{NO}_{2}$ & $0.046 \pm 0.004$ & $0.173 \pm 0.016$ & $0.020 \pm 0.004$ & $0.30 \pm 0.08$ & $271 \pm 4$ & 0.00083 \\
\hline Six channels, high-resolution $\mathrm{NO}_{2}$ & $0.048 \pm 0.003$ & $0.182 \pm 0.012$ & $0.019 \pm 0.004$ & $0.30 \pm 0.08$ & $264 \pm 6$ & 0.00134 \\
\hline $670 \mathrm{~nm}, \mathrm{NO}_{2}=0.3 \pm 0.3 \mathrm{DU}$ & $0.051 \pm 0.004$ & $0.202 \pm 0.037$ & $0.016 \pm 0.004$ & $0.3 \pm 0.3$ & $263 \pm 4$ & 0.00036 \\
\hline $375 \mathrm{~nm}, \mathrm{NO}_{2}=0.3 \pm 0.3 \mathrm{DU}$ & $0.52 \pm 0.003$ & $0.194 \pm 0.023$ & $0.016 \pm 0.003$ & $0.3 \pm 0.3$ & $263 \pm 8$ & 0.00104 \\
\hline $1034 \mathrm{~nm}, \mathrm{NO}_{2}=0.3 \pm 0.3 \mathrm{DU}$ & $0.046 \pm 0.004$ & $0.175 \pm 0.038$ & $0.020 \pm 0.005$ & $0.3 \pm 0.3$ & $271 \pm 5$ & 0.00085 \\
\hline Six channels, $\mathrm{NO}_{2}=0.3 \pm 0.3 \mathrm{DU}$ & $0.048 \pm 0.004$ & $0.184 \pm 0.025$ & $0.019 \pm 0.004$ & $0.3 \pm 0.3$ & $264 \pm 9$ & 0.00138 \\
\hline
\end{tabular}

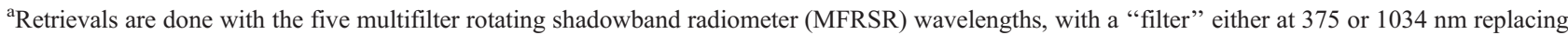
the one at $670 \mathrm{~nm}$ and with filters at both 375 and $1034 \mathrm{~nm}$ replacing the $670 \mathrm{~nm}$ filter and the open filter commonly found in MFRSR devices. The retrievals are tested for three cases: first, retrieving $\mathrm{NO}_{2}$ as well as the aerosol and ozone amounts; second, assuming that $\mathrm{NO}_{2}$ can be measured by high resolution or other means; and third, assuming a broad range of possible values for $\mathrm{NO}_{2}$. For the sake of comparison the mean values are also presented for the 16-channel, high-resolution gas retrievals with margins of errors, considered the best overall retrieval for the RSS data. In the first case the fine-mode effective radius and $\mathrm{NO}_{2}$ show the best agreement, on average, with the 16-channel retrieval when the $375 \mathrm{~nm}$ channel is included, but the optical depths show best agreement, on average, when the $1034 \mathrm{~nm}$ channel is included. In the second case the agreement between the 16-channel retrieval and the retrieval using the $1034 \mathrm{~nm}$ channel is excellent for all quantities. The third case indicates the difficulty in retrieving accurate values of the fine-mode effective radius when $\mathrm{NO}_{2}$ is unknown.

channel allows for the best separation of the coarse- and fine-mode optical depth amounts. The retrieved values of $\mathrm{NO}_{2}$ almost never exceed zero, however, and consequently, the retrieved values of the fine-mode effective radius are too low. The retrievals using the $375 \mathrm{~nm}$ channel produce the best results for $\mathrm{NO}_{2}$ and the fine-mode effective radius, at least on average. Figure 17 plots the values retrieved with five channels, including one at $375 \mathrm{~nm}$, versus those retrieved with 16 channels. It shows that the agreement between the means is unfortunately misleading because the $\mathrm{NO}_{2}$ values simply do not correlate with each other at all. The mean retrieved $\mathrm{NO}_{2}$ value improves when both the 375 and the $1034 \mathrm{~nm}$ filters are used, but the correlation remains poor.

\subsection{Retrievals Using the High-Resolution $\mathrm{NO}_{2}$ Results}

[33] If column amounts of nitrogen dioxide at a given site can be measured using something other than, or in addition to, the direct beam data from a low-spectral resolution device like the MFRSR, then the retrieval results will be more tightly constrained, especially where the fine-mode effective radius is concerned. Table 3 shows that the fivechannel retrieval including a $1034 \mathrm{~nm}$ channel produces excellent agreement, on average, with the aerosol retrieval using 16 channels spanning the full RSS wavelength. The agreement also holds up on a day-to-day basis, as can be seen in Figure 18. The correlation for both coarse- and finemode optical depths is very high, and the slopes are very close to 1 . While not perfect, the correlation coefficients for the fine-mode effective radius and ozone are superior to those using the 375 and $670 \mathrm{~nm}$ channels. For both quantities the agreement appears to be better for lower values than for higher ones.

[34] These results indicate that replacing the $670 \mathrm{~nm}$ channel in an MFRSR with one at or around $1034 \mathrm{~nm}$ can optimize the retrievability of aerosol and ozone information, provided that column $\mathrm{NO}_{2}$ amounts over the detector can be obtained by other means. Naturally, here is where the catch lies. A collocated high-resolution device would perform the job adequately, but additional devices at a network of sites will significantly increase the overall cost of the network.

\subsection{Retrievals With $\mathrm{NO}_{2}$ Set to $0.3 \pm 0.3 \mathrm{DU}$}

[35] Barring an independent means of measuring $\mathrm{NO}_{2}$, it is likely that the best way to deal with $\mathrm{NO}_{2}$ in lowresolution analysis would be to assume an approximate central value with a large margin of error. When this is done for the RSS data, the retrieval results for the coarseand fine-mode optical depths and ozone are not adversely affected, either in terms of their mean value or their margin of error. As Table 3 shows, the mean value of the fine-mode effective radius using five channels, including the one at $1034 \mathrm{~nm}$, agrees nearly exactly with the mean using 16 channels. However, this result depends on assuming a central value that very closely agrees with the actual mean column $\mathrm{NO}_{2}$ value over a given site. Furthermore, the margin of error in the retrieved value of the fine-mode effective radius will necessarily remain very large, on the order of $0.04 \mu \mathrm{m}$ on average. This result unequivocally demonstrates that the ability to measure aerosol size distributions with much precision depends enormously on obtaining as precise measurements of $\mathrm{NO}_{2}$ as possible. Nitrogen dioxide may not exist in large quantities, but its effect on the blue end of the spectrum is too significant to be ignored, and the aerosol size distribution cannot be measured accurately without also measuring $\mathrm{NO}_{2}$ column amounts.

[36] In all three cases it is clear that the five standard MFRSR channels will overestimate the fine-mode optical depth, while underestimating the coarse-mode optical depth and ozone amounts. In addition, the fine-mode effective radius will also be overestimated. Any attempts to retrieve these quantities using the already existing MFRSR data sets will need to somehow circumvent or correct for this systematic error or at least acknowledge the significant 

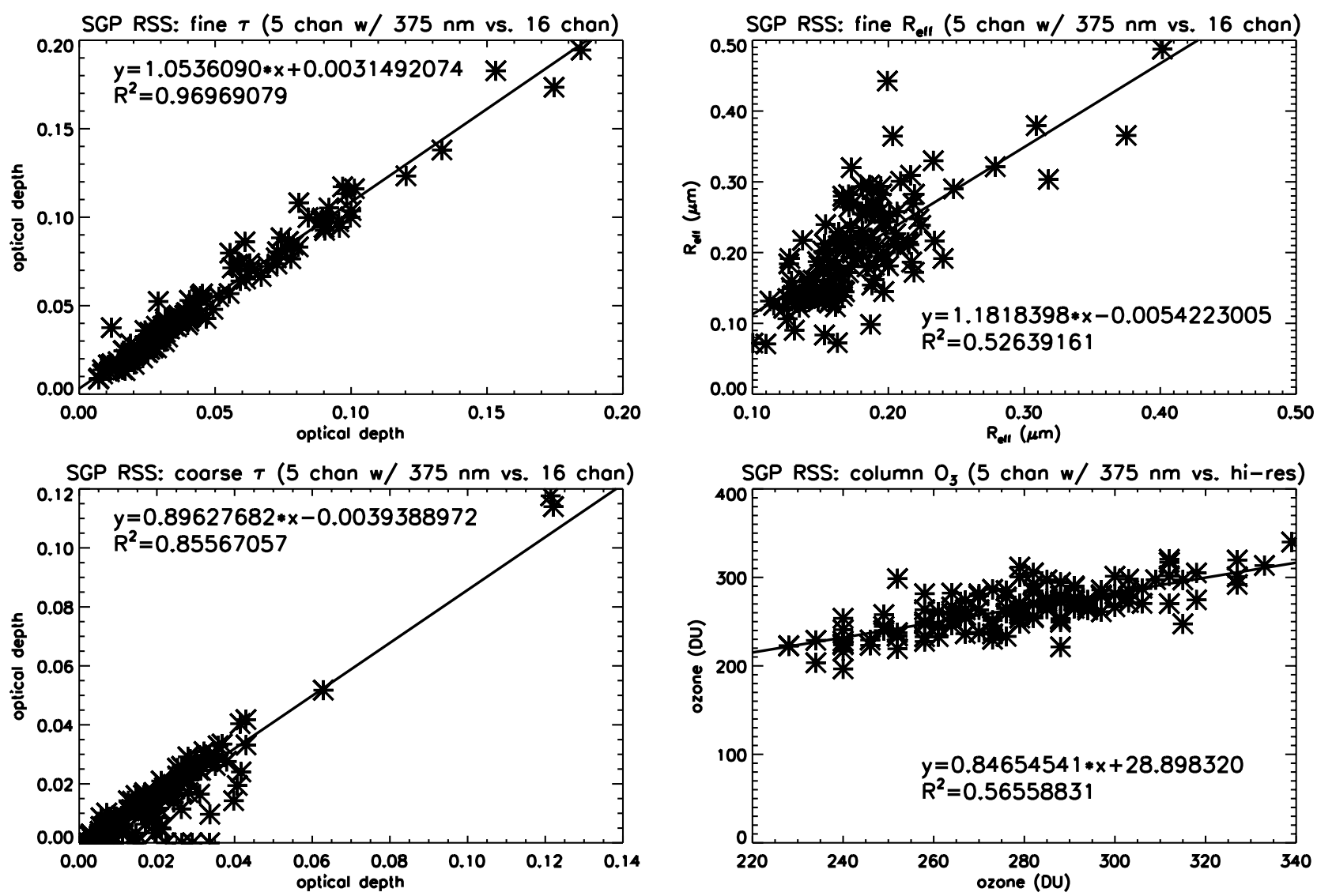

SGP RSS: column $\mathrm{NO}_{2}$ (5 chan w/ $375 \mathrm{~nm}$ vs. hi-res)

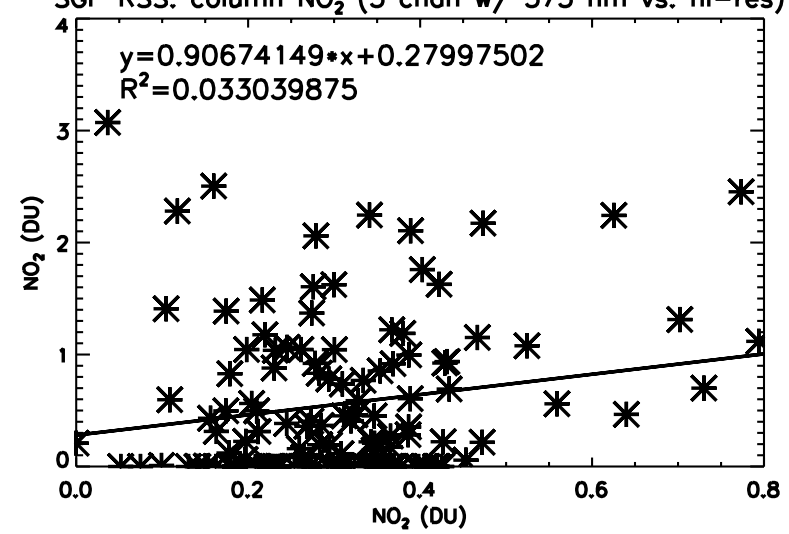

Figure 17. Comparative plots of the retrieved quantities of the five-channel retrieval, including a channel at $375 \mathrm{~nm}$ and simultaneously retrieving $\mathrm{NO}_{2}$, versus the corresponding quantities in the bimodal, 16-channel, high-resolution gas retrieval. Despite the close agreement of the mean values for $\mathrm{NO}_{2}$ and the fine-mode effective radius the correlation is poor, especially for $\mathrm{NO}_{2}$.

limits to the information contained within the data and the errors that result from these limits.

\section{Summary and Conclusions}

[37] The retrieval algorithm designed and implemented for use with RSS data has produced a number of significant results. While plenty of difficulties continue to impede the accurate measurement of aerosol properties, a few things can be said definitively about the aerosols over the SGP site in Oklahoma. First, the aerosol size distribution is at least bimodal, and assuming a single mode in the retrieval will cause significant errors. These errors will be even further compounded if the absorption of nitrogen dioxide at shorter wavelengths is not properly accounted for. Nitrogen dioxide amounts can be reasonably constrained with a highresolution device like the RSS, but the ability to retrieve column $\mathrm{NO}_{2}$ amounts with low-resolution devices like the MFRSR is unlikely to ever be established.

[38] At most, devices whose wavelength ranges do not extend deeply into the near infrared can retrieve three aerosol properties using only direct beam optical depth data. These properties, in a bimodal aerosol distribution, are the coarse- and fine-mode optical depths and the fine- 

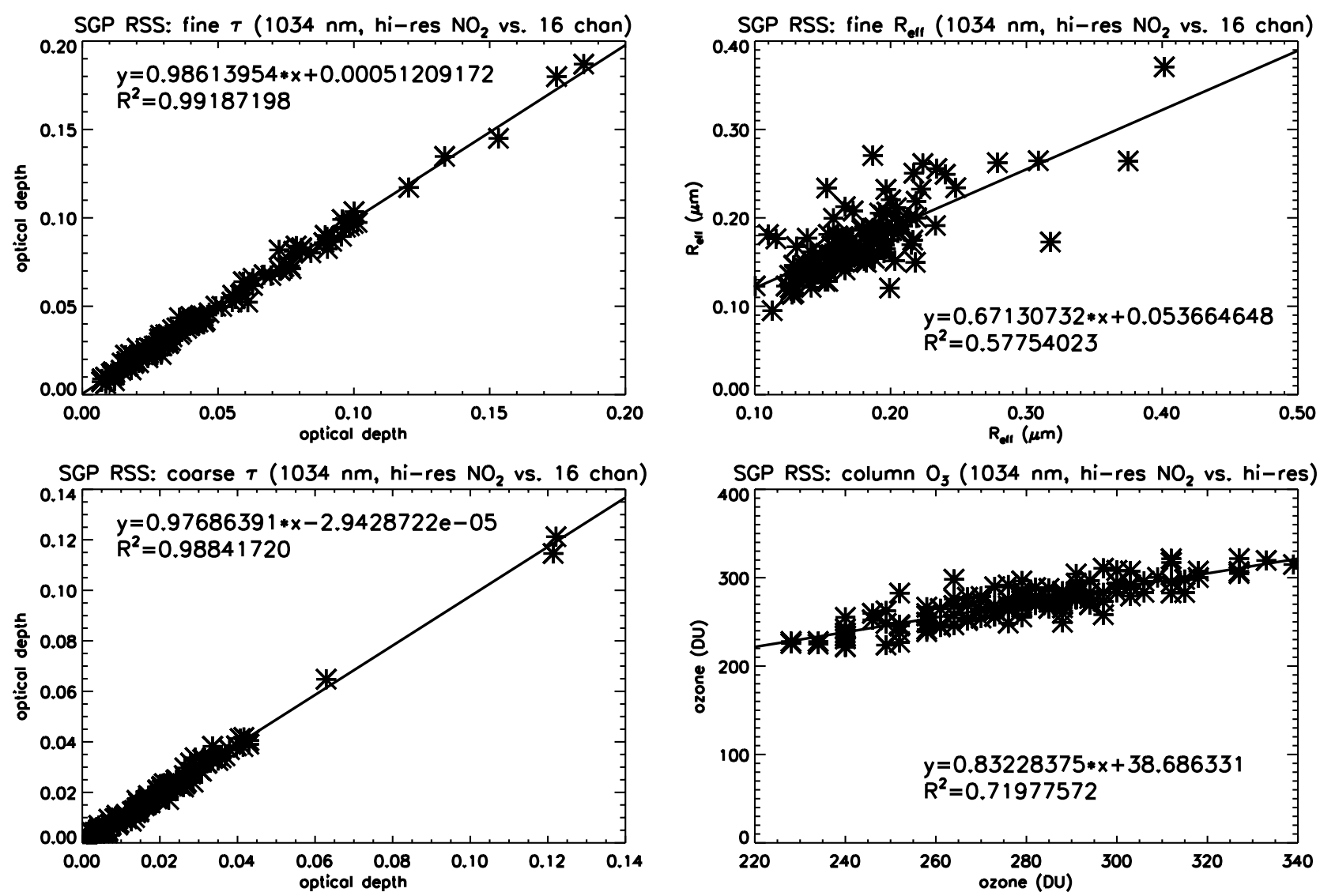

Figure 18. Comparative plots of the retrieved quantities of the five-channel retrieval, including a channel at $1034 \mathrm{~nm}$ and using $\mathrm{NO}_{2}$ values retrieved with high resolution, versus the corresponding quantities in the bimodal, 16-channel high-resolution gas retrieval. Here the overall agreement is very good on a day-to-day level as well as on average. This indicates that a multifilter rotating shadowband radiometer with a $1034 \mathrm{~nm}$ channel substituted for the $670 \mathrm{~nm}$ channel could closely match the retrieval accuracy of the RSS, provided that $\mathrm{NO}_{2}$ can be accurately measured by some alternate means.

mode effective radius. Given this limitation, assumptions need to be made for the properties that cannot be retrieved, and the accuracy of the retrievals depends significantly on the accuracy of these assumptions. When the fine-mode effective variance is constrained to a specific value, the plot of the fine-mode effective radius versus day over the SGP site shows what appears to be an annual cycle. While this result certainly needs to be verified further, it is also important to determine if the assumed variance of 0.1 is reasonably accurate because the retrieved value of the effective radius depends critically on the assumed variance value. In addition, the possibility that the fine-mode effective variance over SGP itself adheres to an annual cycle, because of changes in the physical and chemical properties of the aerosols passing over the site, cannot be overlooked. Perhaps extending the wavelength range of monitoring devices more deeply into the ultraviolet would make the fine-mode effective variance discernible without secondary information, but additional factors like extremely strong ozone absorption, increased Rayleigh scattering, and sulfur dioxide absorption would also need to be considered. The coarse-mode properties cannot really be constrained at all, given the wavelength range of the RSS. To correct this problem, the next generation of devices would need filters extending much more deeply into the near infrared. In the meantime, perhaps particle samplers could reduce the range of possible values for the coarse-mode effective radius. Without improved precision any aerosol analysis of the current generation of ground-based monitoring devices must acknowledge a broad range of possible values for the coarse-mode effective radius, with a corresponding margin of error for the retrieved quantities.

[39] In the retrievals using only five wavelengths to mimic MFRSR capability, not only are the margins of error larger but some discrepancy is introduced into the results as well. Although replacing the $670 \mathrm{~nm}$ channel with one at $375 \mathrm{~nm}$ produces better agreement with full RSS retrievals on average for the fine-mode effective radius and column $\mathrm{NO}_{2}$ amounts, the correlation on a day-to-day basis is insufficient for the fine-mode effective radius and is negligible for $\mathrm{NO}_{2}$. By contrast, replacing the $670 \mathrm{~nm}$ channel with one at $1034 \mathrm{~nm}$ produces good agreement in the retrieved values of the coarse- and fine-mode optical depths even when $\mathrm{NO}_{2}$ is undetermined and excellent agreement for all retrieved quantities if $\mathrm{NO}_{2}$ is known or can be measured by alternative means. Therefore, on the basis of the results of this study, using RSS data as a proxy, it is recommended that the $670 \mathrm{~nm}$ filter in current MFRSR devices be replaced by one with a central wavelength in the neighborhood of $1034 \mathrm{~nm}$. At the very least the retrieval of 
coarse- and fine-mode optical depths will be optimized. If nitrogen dioxide amounts cannot be pinpointed without a large margin of error, the fine-mode effective radius must remain similarly indeterminate. A qualitative analysis should still be possible, allowing for the detection of trends or annual patterns in the data. As for the existing MFRSR data it might be possible to use the $940 \mathrm{~nm}$ channel at sites where the water vapor profiles have been determined and this channel is calibrated to the same accuracy as the others. This will broaden the wavelength range usable in the retrieval, which will improve the overall quality of the results.

[40] Acknowledgments. The RSS at SGP is operated as part of the Atmospheric Radiation Measurement (ARM) Program of the U.S. Department of Energy. The Atmospheric Sciences Research Center at SUNY-Albany processes the data and makes it available for public use. The CIMEL data used by Gianelli [2004] and referred to in this paper were obtained from the AERONET Web site (http://aeronet.gsfc.nasa.gov). The principal investigator of the data is Mary Jane Bartholomew. A PDF of the Gianelli [2004] publication can be found online at http://pubs.giss.nasa. gov/docs/2004/2004_Gianelli.pdf.

\section{References}

Alexandrov, M. D., A. A. Lacis, B. E. Carlson, and B. Cairns (2002a), Remote sensing of atmospheric aerosols and trace gases by means of multifilter rotating shadowband radiometer. Part I: Retrieval algorithm, J. Atmos. Sci., 59, 524-543.

Alexandrov, M. D., A. A. Lacis, B. E. Carlson, and B. Cairns (2002b), Remote sensing of atmospheric aerosols and trace gases by means of multifilter rotating shadowband radiometer. Part II: Climatological applications, J. Atmos. Sci., 59, 544-566.

Box, G. P., M. A. Box, and J. Krücker (1996), Information content and wavelength selection for multispectral radiometers, J. Geophys. Res., $101,19,211-19,214$

Burrows, J. P., A. Dehn, B. Deters, S. Himmelmann, A. Richter, S. Voigt, and J. Orphal (1998), Atmospheric remote-sensing reference data from GOME: part 1. Temperature-dependent absorption cross section of $\mathrm{NO}_{2}$ in the 231-794 nm range, J. Quant. Spectrosc. Radiat. Transfer, 60, $1025-1031$.

Burrows, J. P., A. Richter, A. Dehn, B. Deters, S. Himmelmann, S. Voigt, and J. Orphal (1999), Atmospheric remote-sensing reference data from GOME: Part 2. Temperature-dependent absorption cross section of $\mathrm{O}_{3}$ in the 231-794 nm range, J. Quant. Spectrosc. Radiat. Transfer, 61, 509517.

Colarco, P. R., M. R. Schoeberl, B. G. Doddridge, L. T. Marufu, O. Torres, and E. J. Welton (2004), Transport of smoke from Canadian forest fires to the surface near Washington, D. C.: Injection height, entrainment, and optical properties, J. Geophys. Res., 109, D06203, doi:10.1029/ 2003JD004248

Dubovik, O., and M. D. King (2000), A flexible inversion algorithm for retrieval of aerosol optical properties from Sun and sky radiance measurements, J. Geophys. Res., 105, 20,673-20,696.

Gianelli, S. M. (2004), Retrieving aerosols, ozone, and $\mathrm{NO}_{2}$ using MFRSR, RSS, and CIMEL data, Ph.D. thesis, Columbia Univ., New York.

Grainger, J. F., and J. Ring (1962), Anomalous Fraunhofer line profiles, Nature, 193, 762
Greenblatt, G. D., J. J. Orlando, J. B. Burkholder, and A. R. Ravishankara (1990), Absorption measurements of oxygen between 330 and $1140 \mathrm{~nm}$, J. Geophys. Res., 95, 18,577-18,582.

Hansen, J. E., and L. D. Travis (1974), Light scattering in planetary atmospheres, Space Sci. Rev., 16, 527-610.

Harrison, L., and J. Michalsky (1994), Objective algorithms for the retrieval of optical depths from ground-based measurements, Appl. Opt., 33, $5126-5132$

Harrison, L., J. Michalsky, and J. Berndt (1994), Automated multifilter rotating shadow-band radiometer: An instrument for optical depth and radiation measurements, Appl. Opt., 33, 5118-5125.

Harrison, L., M. Beauharnois, J. Berndt, P. Kiedron, J. Michalsky, and Q. Min (1999), The rotating shadowband spectroradiometer (RSS) at SGP, Geophys. Res. Lett., 26, 1715-1718.

Harrison, L., P. Kiedron, J. Berndt, and J. Schlemmer (2003), Extraterrestrial solar spectrum $360-1050 \mathrm{~nm}$ from rotating shadowband spectroradiometer measurements at the southern Great Plains (ARM) site, J. Geophys. Res., 108(D14), 4424, doi:10.1029/2001JD001311.

Holben, B. N., et al. (1998), AERONET-A federated instrument network and data archive for aerosol characterization, Remote Sens. Environ., 66, $1-16$.

Holben, B. N., et al. (2001), An emerging ground-based aerosol climatology: Aerosol optical depth from AERONET, J. Geophys. Res., 106, $12,067-12,097$.

Intergovernmental Panel on Climate Change (2001), Climate Change 2001: The Scientific Basis, edited by J. T. Houghton et al., 881 pp., Cambridge Univ. Press, New York.

Lacis, A. A., and V. Oinas (1991), A description of the correlated k distribution method for modeling nongray gaseous absorption, thermal emission, and multiple scattering in vertically inhomogeneous atmospheres, J. Geophys. Res., 96, 9027-9063.

London, J., R. D. Bojkov, S. Oltmans, and J. I. Kelley (1976), Atlas of the global distribution of total ozone July 1957-June 1967, NCAR Tech. Note $113+$ STR, Natl. Cent. for Atmos. Res., Boulder, Colo.

Mishchenko, M. I., L. D. Travis, R. A. Kahn, and R. A. West (1997), Modeling phase functions for dustlike tropospheric aerosols using a shape mixture of randomly oriented polydisperse spheroids, J. Geophys. Res., 102, 16,831-16,847.

O'Neill, N. T., T. F. Eck, B. N. Holben, A. Smirnov, and O. Dubovik (2001), Bimodal size distribution influences on the variation of Angstrom derivatives in spectral and optical depth space, J. Geophys. Res., 106, 9787-9802.

Platt, U., D. Perner, and H. W. Patz (1979), Simultaneous measurement of atmospheric $\mathrm{CH}_{2} \mathrm{O}, \mathrm{O}_{3}$, and $\mathrm{NO}_{2}$ by differential optical absorption, J. Geophys. Res., 84, 6329-6335.

Schroeder, R., and J. A. Davies (1987), Significance of nitrogen dioxide absorption in estimating aerosol optical depth and size distributions, Atmos. Ocean, 25(2), 109-114.

Tanré, D., M. Herman, and Y. J. Kaufman (1996), Information on aerosol size distribution contained in solar and reflected spectral radiances, J. Geophys. Res., 101, 19,043-19,060.

Velders, G. J. M., C. Granier, R. W. Portmann, K. Pfeilsticker, M. Weni, T. Wagner, U. Platt, A. Richter, and J. P. Burrows (2001), Global tropospheric $\mathrm{NO}_{2}$ column distributions: Comparing three-dimensional model calculations with GOME measurements, J. Geophys. Res., 106, 12,64312,660 .

B. E. Carlson, S. M. Gianelli, and A. A. Lacis, NASA Goddard Institute for Space Studies, 2880 Broadway, New York, NY 10025, USA. (sgianell@kdist.giss.nasa.gov) 